\title{
Children's Ability to Save: The Effect of Resource
}

\author{
by \\ Hana A. Ziani-Bey \\ B.Sc. University of Ottawa, 2018
}

A thesis submitted to the Faculty of Graduate and Postdoctoral Affairs in partial fulfillment of the requirements for the degree of

Master of Arts

in

Psychology

Carleton University

Ottawa, Ontario

(C) 2021, Hana A. Ziani-Bey 


\begin{abstract}
Saving for the future is an adaptive skill that humans benefit from regularly. Only some studies have explored the factors that contribute to children's saving ability in the early preschool years, such as the nature of the resource to be saved (e.g., symbolic versus non-symbolic). The current study contrasts two savings studies with young children. In one, 63 children aged 3.5-6 years saved a resource itself (i.e., marbles; Kamawar, Connolly, Astle-Rahim, Smygwaty \& Vendetti, 2019), and in another, 53 children aged 4- to 5-years saved a symbol of a resource (i.e., tokens; Jerome, Milyavskaya, Atance \& Kamawar, submitted). Each study included both a control and a budgeting condition where children could make a savings plan prior to engaging in the task, alongside a general planning measure (the Truck Loading task). Overall, children's performance across the two studies did not differ significantly, though the number of resources budgeted approached significance.
\end{abstract}

Keywords: saving, resource, symbol, token, budgeting, planning 


\section{Acknowledgments}

First, I would like to thank my supervisor Dr. Deepthi Kamawar. I am extremely grateful to have had a supervisor as adaptive and responsive as Deepthi, especially given the current times. The Covid-19 pandemic required great shift in my research plans and completion would not have been possible without her time, effort and continuous support.

I am overwhelmingly grateful to have been a part of such a supportive and insightful learning environment, for that I would also like to thank all members of The Children's Representational Development Lab at Carleton University.

I would like to express my gratitude to Emily Jerome as well for agreeing to share her data with me and responding to my inquiries about her research as my analyses would not have been possible without that.

I would like to extend my thanks to Dr. Johanna Peetz, Dr. Melissa Frankel and Dr. Craig Leth-Steensen for agreeing to be on my examination board.

Finally, I would like to thank my friends and family. Thank you to Larbi and Marie for their unconditional love and support. Thank you to Fouzia for always having her door open for me when I needed it. Thank you to my parents for supporting me both financially and emotionally, and my brother for listening to me go on for days on end. I would not have been able to complete this thesis without them. 


\section{Table of Contents}

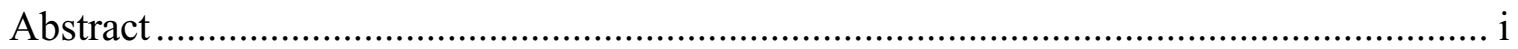

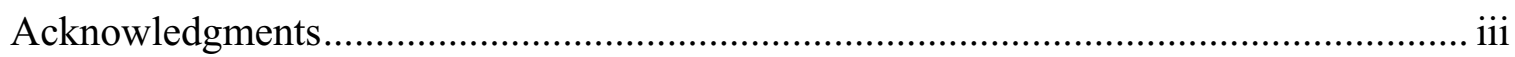

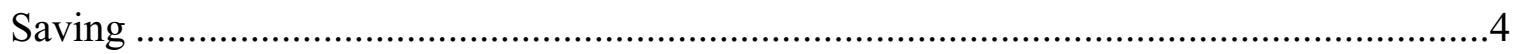

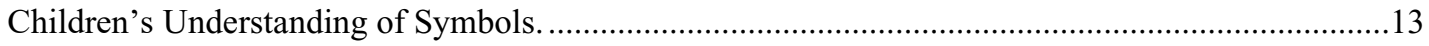

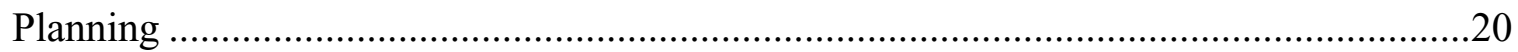

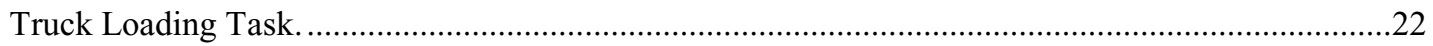

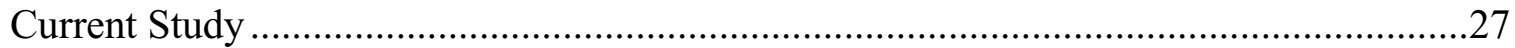

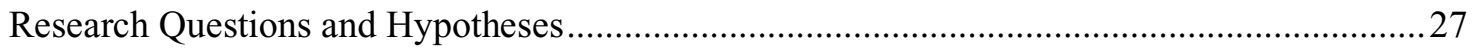

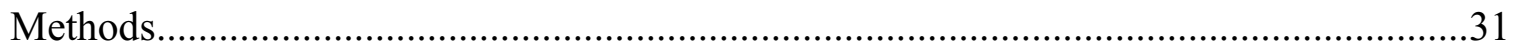

Token Saving Task (from Jerome et al., submitted) …....................................................... 31

Participants.

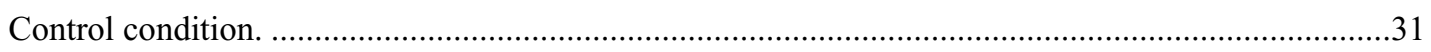

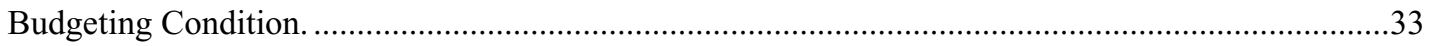

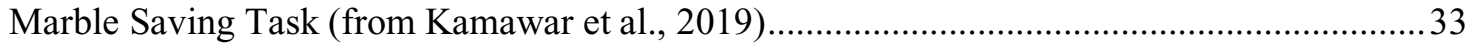

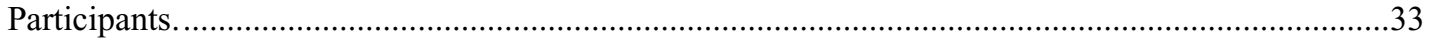

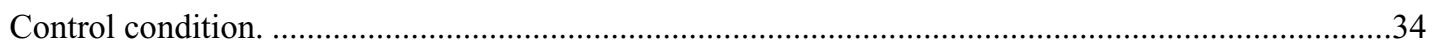

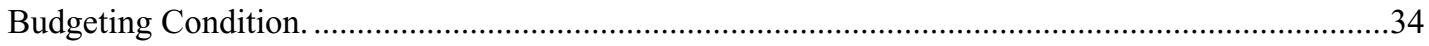

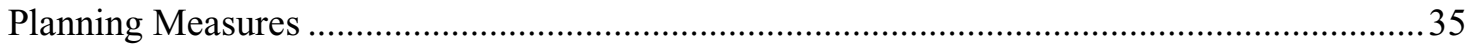

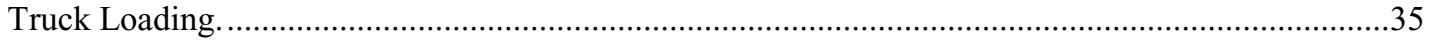

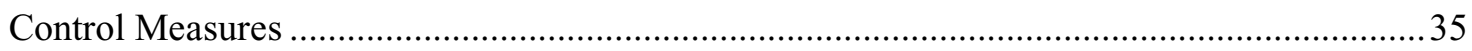

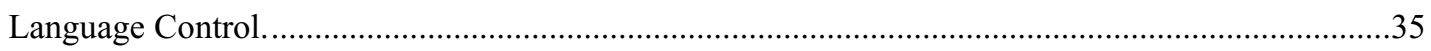

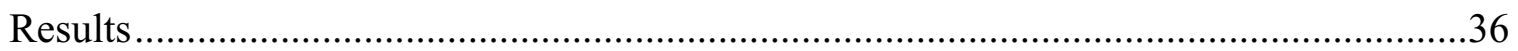




\section{Table of Contents Continued}

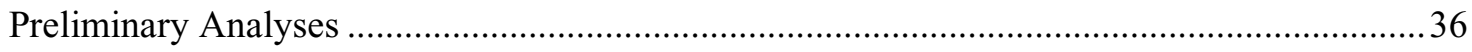

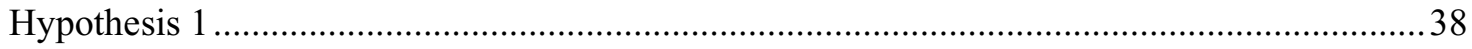

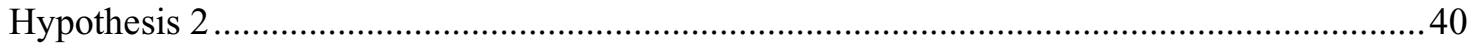

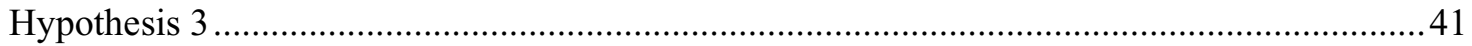

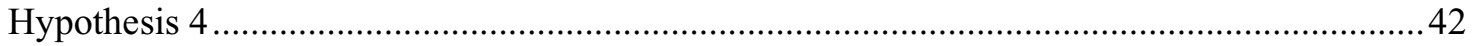

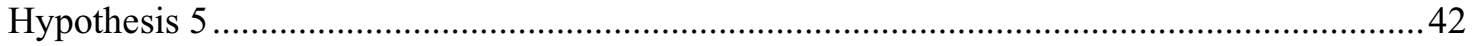

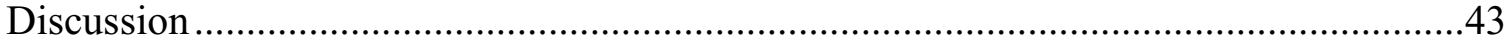

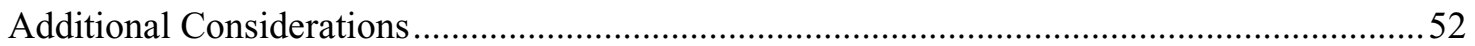

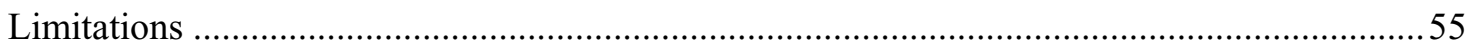

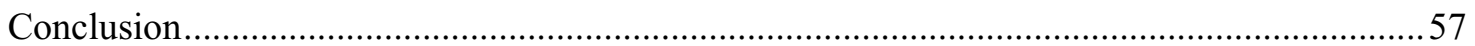

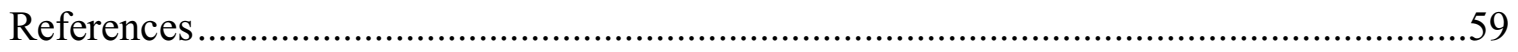




\section{List of Tables}

Table 1. Means and Standard Deviations by Study 36

Table 2. Means and Standard Deviations by Condition by Condition 37

Table 3. Analysis of Between-Group Differences on Age, Planning and Language 38

Table 4. Number of Strong and Weak Savers by Study $\quad 40$

Table 5. Number of Strong and Weak Planners by Study 41 


\section{List of Figures}

Figure 1. Normal Q-Q Plot of Age of Child (in months)

Figure 2. Detrended Normal Q-Q Plot of Age of Child (in months) 


\section{List of Appendices}

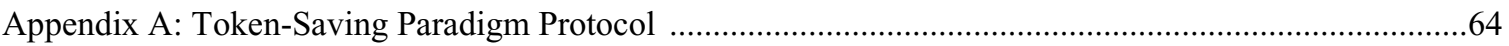

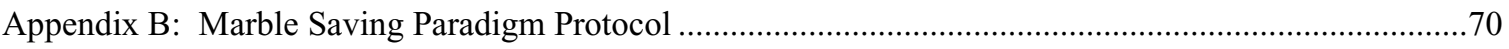

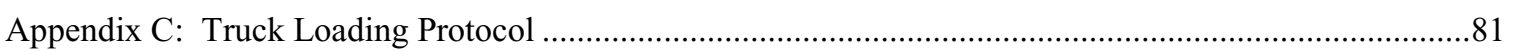

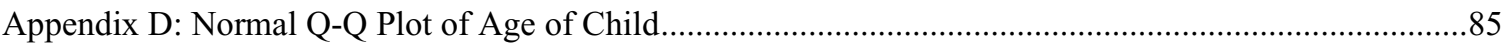

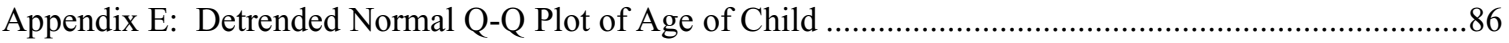




\section{Children's Ability to Save: The Effect of Resource}

Saving for the future is an adaptive skill that humans benefit from regularly. Adults can save money for future needs, time for future activities, and resources for their future. These all meet the general definition of saving: postponement of resources for enjoyment at some point in their future (e.g., Atance \& Metcalf, 2011). Saving skills, as can be noticed in daily life, are highly variable, while it seems some people are able to consistently save, a great number of us struggle to save for the future. The benefits of saving are objectively rewarding, as saving enough money today will secure a better life in retirement, just as allocating more time to my thesis today, will secure more free time for other things in the future.

In order to save for the future, one must be able to anticipate and reason about the future, and make the appropriate decisions, therefore, saving is a fundamentally futureoriented skill. Difficulties in anticipating the future and saving for it can have meaningful consequences on one's saving behaviour. While a stronger understanding of how saving develops as a skill would help researchers to develop methods to improve saving skills, studying saving in young children has historically been overlooked. Only a handful of studies have truly explored the factors that contribute to children's saving ability in the early preschool years (Atance, Metcalf \& Thiessen, 2017; Dueck, Castro, Atance, Kamawar \& Milyavkaya, 2019; Jerome et al., submitted; Kamawar, Connolly, Astle-Rahim, Smygwaty \& Vendetti, 2019; Mazachowsky \& Mahy, 2019; Metcalf \& Atance, 2011). This research has assessed saving performance in relation to a number of other possible predictors, including socioeconomic status and parent income (Dueck et al., 2019), the ability to consider others' and one's own mental states (Atance et al., 2017; 
Jerome et al., submitted), psychological distancing (Jerome et al., submitted), budgeting (Jerome et al., submitted; Kamawar et al., 2019), and other executive functions (Atance et al., 2017; Jerome et al., submitted; Kamawar et al., 2019).

Some of this previous research has assessed the benefits of experience by having children run through two trials of the same savings task, and has found that children's saving performance improves on the second trial (Atance, Metcalf \& Thiessen, 2017; Kamawar et al., 2019; Metcalf \& Atance, 2011), indicating the value of experience. This would suggest that children pull episodically from past experience (also known as episodic retrospection) to make decisions for the future. Anticipating and making appropriate decisions for the future can be accomplished by reasoning about past experiences and choosing the best approach to a situation accordingly. This is difficult if one does not have a past experience to reference. Young children live in relatively controlled environments, where resources are typically pre-portioned for them and the need to save is not a part of their daily lives, and it may very well be that children must first experience the consequences of inefficient saving before they can implement saving.

It is important to distinguish saving from other relevant, future-oriented cognitive skills, such as the ability to delay gratification. Delay of gratification is considered a type of inhibitory control skill. Inhibitory control (IC), also referred to as inhibition (Bull, Espy \& Senn, 2004; Carlson et al., 2004) is divided into two categories: delay and conflict. Delay inhibition involves holding off on a prepotent response for some period of time. This is also known as delay of gratification (DoG). It is important to distinguish saving from DoG, as they are seemingly quite similar. A well-known DoG task is the Marshmallow Task (Mischel, 1989) in which children must inhibit consuming a desirable 
item for a set time in order to receive a greater quantity of that item. More specifically, children are given one marshmallow and told if they wait long enough without eating the marshmallow, they can have that one, along with a second one. The experimenter leaves for up to fifteen minutes (depending on the child's ability to delay) before returning with the second marshmallow. Children who are able to wait until the experimenter comes back are said to have greater inhibitory control as they were able to delay a small immediate reward in favour of a larger long-term reward.

While it may appear that DoG tasks and saving tasks are tapping the same skill, one study has found that they are not equivalent (Kamawar et al., 2019). DoG requires the ability to withhold a prepotent response and act on it at a later point in time, when it is more beneficial. For example, in the marshmallow task children are initially given one marshmallow, but waiting provides them with a second one in addition to the one they were initially offered. Saving, on the other hand, requires one to forego something in the moment, in order to get something different in the future. For example, saving your coffee money means you will not currently have coffee, but will be able to afford a weekend away later. Thus, while conceptually similar, saving and DoG are two different skills. Further, the one study to date which has examined both skills together did not find that they were related (Kamawar, et al., 2019). Thus, further examination of saving as an important future-oriented skill, in its own right, is valuable.

While research on young children's saving ability using age-appropriate tasks is relatively new, it is worth noting that the studies to date have used two forms of savings tasks: ones in which children are to save, or spend, the limited resource itself (e.g., marbles; Atance, Metcalf, \& Thiessen, 2017; Kamawar et al., 2019; Metcalf \& Atance, 
2011) and those which require children to save, or spend, a symbol of a resource (e.g., tokens; Dueck et al., 2019; Jerome et al., submitted, Sonuga-Barke and Webley, 1993). Is it unclear, however, whether children's saving behaviour is similar across the two types. No previous research, to my knowledge, has directly compared children's saving performance when dealing with these different types of saving situations. Thus, the goal of my research is to compare children's performance on these types of savings tasks (using data from Kamawar et al., 2019 and Jerome et al., submitted).

Originally, the goal of my thesis was to assess the influences of future-oriented conversations on saving behavior. Due to the current Covid-19 situation, I will no longer be assessing this skill and I will instead be analyzing data previously collected in Dr. Kamawar's lab examining young children's saving performance using two different savings tasks. Before turning to the specifics of my study, I will begin by describing the past literature on young children's ability to save and a relevant cognitive skill (planning).

\section{Saving}

As mentioned previously, research on young children's saving ability has been rather scarce, however a handful of recent studies have explored the progression of this skill in the preschool years. One of the earliest studies to investigate saving behaviour in children was Sonuga-Barke and Webley (1993). These researchers assessed 4-, 6-, 9- and 12-year-olds on a board game saving task in which children were given tokens. These abstract tokens could either be spent during the game on less desirable rewards, or saved for a larger reward at the end of the game. This game was fairly complex and there were a number of rules about what could, and could not, be done. The researchers found that 
older children performed significantly better than younger children, with 4-year-olds performing quite poorly, suggesting that they were not capable of saving for their future selves. However, a limitation of this study, as it relates to the youngest group of participants, is that 4-year-olds' limited performance may have been due to game complexity, and therefore this task may have underestimated their saving abilities. What was needed was a task designed to be more suitable to detect earlier aspects of saving ability in younger children.

Metcalf and Atance (2011) addressed this limitation by developing a simpler task which they demonstrated to be suitable for use with preschoolers. These researchers examined whether preschoolers can save to benefit their future selves using their novel marble-run savings task, and also assessed whether saving was related to Theory of Mind (ToM) ability (the ability to consider mental states, see Wellman, Watson, \& Cross, 2001). In their savings paradigm, children had to save the limited resource itself, and not an abstract representation of it. Before beginning with trials, children were familiarized with two rooms: the blue room (containing a large marble run) and the red room (containing a small marble run). Children first visit one of the rooms and are shown that a marble can only go down the run once. They are given a demonstration to show how the marble goes into a closed box at the end of the run and cannot be used again. This is then repeated in the next room. Then the trials begin. The experimenter explains to the child that they will be staying in one of the rooms for three minutes and they will next be staying in the other one (the order of the room varied by condition). They are then given three one-time-use marbles, told they may spend them in either game as they please, and then taken to their first room. In order to keep their interactions with the child to a 
minimum, the experimenter tells the child that they are going to do some work until the timer rings. After the three minutes are up, the child, along with any marbles they had saved, are moved to the next room for three minutes. The researcher then indicates that she 'found' three more marbles, and the entire procedure is repeated. The measure of interest in Metcalf and Atance (2011) is the number of marbles children saved for the second room.

This study included two conditions; in the more-rewarding-future condition the small marble run first and the large one second, while in the more-rewarding-present condition, the presentation of the runs was reversed. In the latter condition, the incentive to save marbles is reduced, since the larger marble run is presented first, however, the authors reasoned, the incentive should still be present, as it is still undesirable to be in the room with the small marble run and have no marbles to play with for three minutes. The researchers included two trials for each condition and were interested in seeing whether children were able to reflect on a past experience to make decisions that benefit their future selves.

The results showed that, in trial 1, the majority of children failed to save any marbles for their preferred run (in the more-rewarding-future condition 39\% of children saved marbles for their preferred run, while in the more-rewarding-present condition $29 \%$ saved). The researchers interpreted this to mean that perhaps children understand that it is important to save, but lack the necessary cognitive skills to implement it. For example, children may have found it challenging to inhibit their urge to spend their marbles right away, reflecting demands in inhibitory control. Interestingly, children saved significantly more marbles during the second trial than the first trial (respectively, $72 \%$ vs. $39 \%$ in the 
more-rewarding-future condition; and 63\% vs. 29\% in the more-rewarding-present condition). These results demonstrate that children benefitted from prior experience as they were better able to save adequately for their future selves after only a single trial. The researchers also found that children saved significantly more marbles in the morerewarding-future condition, than the more-rewarding-present condition. This makes sense, as it is more beneficial to save for a more-rewarding future than a less-rewarding one.

Contrary to their predictions, Metcalf and Atance (2011) failed to find any main age effects. The researchers suggested that although older children may not have saved more marbles than younger children, they may have waited longer than younger children before spending their marbles. The researchers found that children waited longer to spend their marbles in the first room in trial 2 than in trial 1, but also found that older children did not wait any longer than younger children before using their marbles.

The researchers suggested a number of reasons for these null results. First, they argued, it is likely that saving abilities emerge in the preschool years and variability in saving is much higher during that period. They support this claim by pointing to adult studies which have demonstrated that this ability typically varies, and this variability may stem from an earlier point in development. Second, they pointed out that it may have been that spontaneous saving is too challenging for young children. Third, they noted that it may also be the case that three marbles is not sufficient enough to capture adequate variability. The researchers addressed these limitations in a follow-up study (Atance, Metcalf, \& Thiessen, 2017). Importantly, this study demonstrated that preschoolers are, in fact, capable of saving a limited resource to benefit their future selves, suggesting that 
the earlier work with this age group did underestimate their ability (Sonuga-Barke \& Webley, 1993)

Atance, Metcalf and Thiessen (2017) assessed 3-, 4-, and 5-year-olds' saving skills with and without a verbal prompt, with only one trial, and included five marbles rather than three. The researchers used the same two-room marble run saving task as in Metcalf and Atance (2011) but, this time, with three conditions: spontaneous, prompted and a control. In the spontaneous condition, the procedure was identical to that in Metcalf and Atance (2011). In the prompted condition, children were given a verbal prompt indicating the possibility of saving prior to completing the task; more specifically, they were told "If you want to, you can use all of your marbles in the red room or you can save some marbles for the blue room" (p.72). The control condition was used to assess children's preference for either the small or large marble run, which were presented together, and found that children preferred the large one.

The researchers predicted that children would perform better in the prompted condition, relative to the spontaneous one, as previous research has shown that verbal prompts improve children's prosocial decision making as it allows them to stop and reflect on the situation (Hall, Jones \& Claxton, 2008). As predicted, children in the prompted condition saved significantly more marbles than in the spontaneous condition. Thus, alerting children to the options of either spending or saving, improved saving behaviour. The authors note that when saving, one must weigh the current cost, and future benefit to decide which they deem more valuable, either avoiding a current cost, or supporting a future benefit. It may have been challenging for children to actively select 'saving' versus 'spending' as their goal and a prompt may have reduced the challenges of 
spontaneously weighing in the costs and benefits of choosing to save. Notably, it remains unclear whether children had developed an explicit savings plan prior to engaging in the task.

Interestingly, the researchers found that saving ability differed as a factor of age, with older children saving significantly more marbles than younger children. This suggests that the previous null findings in Metcalf and Atance (2011) may have been either a result of insufficient marbles for adequate variability, or because spontaneous planning is indeed too challenging for young preschoolers to capture variability. Notably, no interaction effects were found to be significant, suggesting older children did not benefit more from a prompt than did younger children, or vice versa.

Atance et al. (2017) also assessed saving performance in relation to two other cognitive skills: inhibitory control-conflict and working memory (the ability to hold information in mind while simultaneously processing information (Baddeley \& Hitch, 1974).They had expected to find a relation because in the process of saving, one reasons about multiple pieces of information to create a plan and exercises their self-control to implement said plan, it is, therefore, reasonable to expect a relation between aspects of executive function (EF) and saving behaviour. However, the researchers failed to find a significant relation between inhibitory control and working memory with saving. It is important to note that Atance, Metcalf and Thiessen (2017) assessed conflict inhibition rather than inhibitory control-delay (also known as DoG). Considering past research on saving in adults has found a relation between self-control and saving (Nyhus \& Webley, 2001; Rabinovich \& Webley, 2007),) a study assessing the relation between DoG and saving in children was warranted. 
Another cognitive skill that has been considered to be relevant to saving performance is planning. Planning refers to one's ability to execute a sequence of actions to accomplish a goal in the future (Owen, 1997). In the case of the two-room paradigm, having sufficient marbles to play with in the second room would be the goal, and adequate saving of the appropriate number of marbles would be the necessary action to accomplish said goal. Thus, it is possible that saving includes a planning component, or that planning skills may have a marked relationship with saving. It is also possible that saving includes an aspect of self-control. That being said, it is unclear whether children's failure to save in Atance et al. (2017) can be attributed, at least in part, to weak planning abilities or a limited ability to delay gratification.

Kamawar et al. (2019) assessed children's saving abilities using the same tworoom marble run paradigm as previous research (Atance et al., 2017; Metcalf \& Atance, 2011) while including children from a wider age range (3.5- to 6-year-olds). The researchers aimed to assess the effects of budgeting (a savings/spending plan) and prior experience (the effect of trial 1 on trial 2) on saving performance, and examine the relation between saving and general planning skills and inhibitory control-delay (DoG). They included a similar savings paradigm to Atance et al. (2017)'s spontaneous condition with the exception of two changes: (1) children were given the opportunity to try both marble runs prior to testing (in order to ascertain to children that each marble went into a box at the end of the run and could not be used again); and (2) children were asked to evaluate which run they liked best - this run was used as their more-preferred run. Further, the study included two conditions: the budgeting condition and a control condition. In the control condition there were no other manipulations, while in the 
budgeting condition, children were given the opportunity to create a savings plan prior to engaging in the task.

In the budgeting condition, participants were given a small tray containing two bowls. Propped behind each was a photo of one of the marble runs. Children were told they could decide the number of marbles they wanted to use in each room by putting the amount of marbles they wished to use in the corresponding bowls. The researchers avoided words like 'save' or 'plan' and did not give any feedback on children's budget. Children were then taken to the room with their less-preferred marble run, followed by the room with their more-preferred one, each for 3 minutes, as in Atance et al., (2017). Children took both bowls with them to each room in order to highlight the potential options of either following through with their savings plan, or deviating from it. The same procedure was repeated for a second trial with five new marbles. The researchers were interested both in how many marbles were saved for the preferred run, and whether any were saved at all. To this end, children were coded as 'savers' if they saved at least one marble for their preferred marble run, and were coded as 'consistent savers' if this was done across both trials. Children were also labelled as 'planners' if they planned to save at least one marble for their preferred run, and 'consistent planners' if this was done across both trials. These classifications were used because it is unclear which saving plan is the most beneficial. The researchers noted that it is perhaps more beneficial to save some marbles for the future game, and spend some marbles now in order to avoid being bored in the present. That way, they are also able to play both games, rather than play only one. Given it is unclear at what point the conflict between saving and spending becomes non-adaptive, the researchers categorized children as 'savers' and 'planners'. 
Alongside, delay of gratification was also assessed in relation to saving using a delay sticker choice task in which children had to decide on receiving a smaller reward immediately ( 1 sticker) or a greater reward later ( 4 or 5 stickers, varied across trials). This was in order to evaluate whether children's failure to save adequately for their future selves was a result of poor planning, or poor self-control.

The overall effects of prior experience replicated that of Metcalf and Atance (2011), children in the control condition saved more marbles on their second trial, demonstrating the benefit of experience. Also, children in the budgeting condition saved more marbles than children in the control condition on the first trial, demonstrating that children's saving ability benefitted from the opportunity to create a budget. Moreover, most planners were also savers, in that most children who planned to save at least one marble for their preferred run, did indeed save at least one marble. Further, those who were consistent planners (i.e., planned to save during both the first and second trial) were also consistent savers (saved at least one marble for their more-preferred game on both the first and second trial).

Contrary to Atance et al. (2017), but consistent with Metcalf and Atance (2011), Kamawar et al. (2019) neither found an effect of age nor any interactions between age and either condition or trial. The researchers did, however, find an interaction between trial and condition, with children in the control condition benefitting more from experience than in the budgeting condition. The researchers noted that prior experience did not appear to improve saving skills much beyond the opportunity to budget.

Based on the research using the marble savings task, and some variants, it is clear that even by the preschool years children demonstrate the ability to save a limited 
resource to benefit their future selves (in the very near future). These findings stand in contrast with earlier work in this area (Sonuga-Barke \& Webley, 1993). However, while children do often have situations in which they can benefit from saving a limited resource (e.g., saving Halloween chocolate), they also have to become able to deal with situations in which they have to save a representation of value, such as money. The two-room marble run paradigm that has been described up to date only allows for assessment of one type of saving: saving a resource itself for future use. However, it does not address other kinds of saving situations that children will have to become able to deal with, namely situations that require them to save a symbol of a resource (i.e., a token). I now turn to this type of saving situation, by first briefly reviewing children's ability to deal with abstract symbols and then discussing research investigating young children's ability to save using more abstract saving tasks.

Children's Understanding of Symbols. As mentioned above, recent research has also employed savings tasks in which children must save a symbol of a limited resource for future use (i.e., a token; Dueck et al., 2019). A symbol can be defined as "something that someone intends to represent something other than itself' (DeLoache, 2004; p.66). Symbols relate to their referents (what they are intended to represent). This relation can be iconic or arbitrary. For example, a photo of an airplane to represent the airport is an iconic symbol. It is clear from the photo that the symbol is something to do with airplanes and the representation and the referent are related by way of resemblance. An example of an arbitrary symbol, however, is a number sign "\#” being used to represent the word 'number'. There is nothing inherent about this symbol '\#' that relates it to the word number, other than a collective agreement to refer to it as such. Children's ability to 
understand symbols develops over the course of preschool years, and a large body of research suggests that they become quite competent at making and interpreting a variety of symbols during this age period (e.g., Bialystok et al. 2000, DeLoache, 2004, etc.)

Until very recently, savings research did not include the use of symbols of a resource in a pared-down task designed for preschoolers. Such a task is useful, however, as it is more akin to spending money in real life. Although Sonuga-Barke and Webley (1993) assessed children's saving skills using a token-based savings task, with tokens being symbolically valuable, the task consisted of many rules and was considerably challenging for young children. What was needed was a task that assessed children's saving ability of a symbolic resource, but that was simple enough for young children to understand. Dueck et al. (2019) developed such a task. In their novel token savings tasks, children had to save/spend a representation of a limited resource (rather than the limited resource itself), approximating our real-world conception of saving money.

Dueck et al. (2019) assessed 3- to 7-year-olds' performance on a token-based saving task and evaluated its relation to household income and parental education. In this token-based savings task children play two consecutive games involving using tokens to get prizes. Children were given five tokens and told they will be playing two games for three minutes each, the raisin game and the Smarties game, beginning with their lesspreferred game (for most, that was the raisin game). They were shown that by placing a token in a slit in a closed box a prize can be chosen from the corresponding basket (that either contained raisins or Smarties). They were allowed to engage with the raisin game for three minutes, and then subsequently with the Smarties game. They were told they may use the tokens in either the first game (less-preferred prize) or second game (more- 
preferred prize) and could not receive more tokens after they have all been spent, nor could they re-use any tokens. Similar to Atance et al., (2017), this study included two conditions: the prompt condition and a control condition. In the prompt condition, the procedure was identical but alongside being told they will receive five tokens, children were also told explicitly that these tokens could be used in either game. This task is similar to the marble run task in that the second game is more-preferred than the first, and it is, thereby, encouraging to save.

As the researchers predicted, children in the prompt condition saved significantly more marbles than those in the control condition. This supports previous work demonstrating that children's saving skills benefit from verbal prompts (Atance et al., 2017; Kamawar et al., 2019). Importantly, it demonstrated that young children were able to save a symbolic resource and further suggests that their failure in Sonuga-Barke and Webley's (1993) work was not due to the use of symbols but was more likely to be caused by their task complexity.

Jerome et al. (submitted) further extended the use of this saving task assessing performance on this measure and its relation to planning, the effect of budgeting, and psychological distance. Given that the current thesis will analyze some of the data from this study, its method will be described in some detail.

Jerome et al. (submitted) employed Dueck et al.’s (2019) token-based saving paradigm to explore the impact of creating a budget, both for oneself and for another as an extension of Kamawar et al. (2019). Budgeting for another was expected to improve children's performance due to the benefits of psychological distancing. Psychological distancing refers to mentally separating oneself from a current situation allowing for 
greater consideration of future goals, and more flexibility in one's thinking (Lee \& Atance, 2016). Research suggests that children with immature future-oriented cognition are better able to make future decisions for another person than themselves. For example, Russel et al. (2010) examined children's future-oriented cognitive abilities by first having them play a game of blow football that required a box and a straw. Children were asked to select the appropriate items needed for themselves and also asked what would be needed if another child were playing the same game. Children, remarkably, selected the correct items more often when considering another child than when considering themselves. Another study (Bélanger et al., 2014) investigated pre-school children's ability to name items they would like when they were "all grown up", (e.g. juice vs. coffee), for themselves as well as for another child. The researchers found that children were better able to anticipate the future desires of a peer than of themselves. This, again, indicates that children may be better able to reason about another's future than their own. Jerome et al. (submitted) investigated children's ability to create a budget and implement it and also administered measures of planning and ToM, using the same token-based savings task as in Dueck et al. (2019) but substituting stickers and toys for Smarties and raisins (this was done to make the study compatible with daycare rules).

This study included three conditions: budgeting-self, budgeting-other and a control. All conditions began with an introduction to both games, the toy game (to be played on a blue tray) and the stickers game (to be played on a green tray). A preference check was taken to ensure the least-preferred game was played first. Each tray included a colour-matched bowl which contained the prizes, and a colour matched small box where the tokens were to be placed. Children were told to choose their five favourite stickers 
and their five favourite toys (this was done to ensure that both games included desirable options), then to put them in the corresponding bowls. They then indicated which bowl contained their preferred prizes. The experimenter then chose a sticker and a toy of their own to place in each of the bowls (to be used as for demonstration purposes). The children were then presented with seven tokens, two of which the experimenter used as a demonstration, leaving five remaining tokens. In the demonstration, the experimenter showed each child how the game worked by inserting a token into a box and taking a prize from the corresponding bowl (the researcher always removed the item they had placed in the bowl). Children then answered questions to make sure they understood the rules of the game and then proceeded to the task itself.

In the control condition, children proceeded to play their least preferred game for three minutes, followed by their most-preferred game for another three minutes. In the two budgeting conditions (self and other), children were given the opportunity to create a budget by allocating tokens for use in the games. In the budgeting-self condition, children needed to create a budget for themselves, while in the budgeting-other condition children were expected to create a budget for someone else. In the budgeting-self condition the experimenter showed participants both trays and placed two small baskets (green and blue) in front of them. Children were given five tokens and told they may decide how many tokens they would like to use for each game and to place the desired amount in the corresponding bowls. The experimenter then proceeded to tell the children they would be playing each game, one at a time, for three minutes. Children had access to all of their tokens throughout both games. 
In the budgeting-other condition, before creating their budgets, children were shown a photo of an age-matched gender-neutral child ('Sam') and told that Sam had similar preferences as them and was 'very good at these kinds of games'. They were told to pretend they were 'Sam' (to create psychological distance). They were given a bracelet with Sam's name and photo on it and asked where Sam ought to put tokens. The rest of the procedure remained identical to the budgeting-self condition. This method was based on other studies demonstrating the benefits of psychological distancing with this age group. For all three conditions, the researchers were interested in the number of tokens saved for the preferred game, and again, whether any were saved at all.

After completing her thesis, Jerome went on to collect more data. These results replicated some of the findings of Kamawar et al. (2019) in that children in each of the budgeting conditions saved significantly more tokens for their more-preferred game than did children in the control condition (Jerome et al., submitted). This demonstrated that children's saving performance markedly improves when given the opportunity to create a savings plan, even when dealing with more abstract saving. Post-hoc tests revealed that participants in the budgeting-other and budgeting-self condition did not save a significantly different number of tokens. Contrary to their hypothesis, Jerome et al. (submitted) did not find that children in the budgeting-other condition saved significantly more tokens for their more-preferred game compared to children in the budgeting-self condition. The researcher suggested that one possible reason for this may be that children may have spent the tokens according to their own personal desires disregarding that they were expected to pretend to be someone else. 
Overall, studies have demonstrated mixed findings in the relation between age and saving ability. As mentioned above, Metcalf and Atance (2011) found that older and younger children did not differ significantly in their saving abilities. Atance et al. (2017) raised the possibility that the lack of age effects found in the previous study, Metcalf and Atance (2011), may have been because only three marbles were used. They deemed this insufficient for adequate variability and decided to use five marbles instead. After running a linear trend analysis, Atance et al. (2017) found that saving skills improved significantly with age. However, Kamawar et al. (2019), similar to Atance et al. (2017), also included five marbles and did not find the same effect. It could be that indeed children's saving ability does not demonstrate variability until a later age, or that a prompt has facilitated children's ability to reason about saving and, has in turn, allowed for more variability. That being said, Dueck et al. (2019) assessed children's saving ability with a prompt and found results consistent with Atance et al. (2017), (i.e., that saving improved as a factor of age), more older children were classified as 'savers' than younger children. This is contrary to the findings in both Metcalf and Atance (2011) and Kamawar et al. (2019), where no significant age-related effects on saving were found. These mixed findings are noteworthy as other cognitive skills appear to develop rapidly during the preschool years and saving may not be a skill that develops at a similar rate. More research is needed to understand how saving skills develop in the preschool years. Particularly, no research to date has assessed performance differences between two types of savings tasks.

Another focus of the current study is to investigate the role of planning across the two types of savings tasks (saving the resource itself versus saving a symbol of a 
resource). Planning is another cognitive skill that has been investigated in relation to saving (Kamawar et al., 2018; Jerome et al., submitted). Planning is a complex executive skill that enables humans to execute a series of steps to accomplish future goals (McCormack \& Atance, 2011) and can be considered an inherently future-oriented skill.

\section{Planning}

Planning is one of the subsets of a broader set of skills dubbed executive function. Executive function (EF) refers to a set of skills that together control and regulate cognitive and behavioural activities (e.g., Carlson, Moses \& Claxton, 2003). Among the subsets of executive function alongside planning are: cognitive flexibility (i.e., the ability to cognitively adapt to changes), working memory (i.e., the amount of information one can keep in mind and manipulate at a given time), and inhibitory control (i.e., the ability to hold back a prepotent response) (Pellicano, 2007; Willoughby et al., 2010).

Previous research has demonstrated a link between planning and future-oriented thinking (Atance \& O’Neill, 2001; Friedman \& Scholnick, 1997; Haith, 1997). Planning is a relatively complex executive skill that enables humans to accomplish future goals (McCormack \& Atance, 2011). Due to a variety of definitions and operationalizations, there does not appear to be a fully agreed upon definition of what planning is, but the construct can be generally understood as the executed predetermination of goal-directed behaviours used to achieve a specific goal (Owen, 1997). Planning is also discussed as an executive function skill, as mentioned above, with its emergence beginning with motor planning in infancy (Claxton, Keen and McCarty, 2003; McCormack \& Atance, 2011). Motor planning refers to early indicators of behaviour requiring advanced thought (McCormack \& Atance, 2011), such as adjusting movements for a future need. Claxton, 
Keen and McCarty (2003) tested 10-month-old infants on an interesting task that compared speed of approach towards an object subsequently intended to be either put into a narrow tube or thrown into a large tub placed on the floor. Remarkably, infants changed the speed of their approach, just as adults would, depending on what they intended to do with the ball afterwards. If they intended to throw the ball in the tub, their approach was faster, while when they intended to place the ball down the tube their approach was slower, thereby demonstrating they could plan their motor movements according to their future intentions (i.e., goals).

It is expected that planning may be related to saving because in order to effectively execute a savings plan, one must be able to create one in the first place. Some research has assessed the relation between saving and planning (Kamawar et al., 2019; Jerome et al., submitted). This research has assessed children's planning ability in two ways; by (1) using one standard planning measure; and (2) allowing children to create a savings plan (i.e., a budget). This research demonstrated mixed findings. The researchers found that performance on the Truck Loading task (a common planning measure to be described in more detail later) both related significantly to saving ability (Kamawar et al., 201) and did not relate to saving ability (Jerome et al., submitted). However, children who created a savings plan were better able to save (Kamawar et al., 2018; Jerome et al., submitted). Hence, the relationship between planning ability and saving is still unclear and merits further investigation (or in this case, a comparison of its relation to the two types of savings examined).

The type of planning ability relevant to the current thesis typically develops into the preschool years and becomes increasingly apparent by 3 - to 4-years of age (e.g., 
McCormack \& Atance, 2011). These skills continue to develop over the course of childhood with rapid gains in children over five years of age (McColgan \& McCormack, 2008). A number of measures are used to assess planning in preschool children, each approaching the construct in a slightly different way. The main ones used with this age group include: tower tasks (e.g. Tower of Hanoi; Simon, 1975), sequencing tasks (e.g., Truck Loading task; Fagot \& Gauvain, 1997), maze tasks (e.g., mazes task; Wechsler, 1989), and route planning tasks (e.g., Kitten delivery task; Fabricius, 1988). I will describe the Truck Loading task here as it is the task that was included in both Kamawar et al. (2019) and Jerome et al. (submitted) - the two studies I will be comparing for the purposes of my thesis.

Truck Loading Task. In this task children are asked to pretend they are letter carriers using a toy mail truck. They are to deliver coloured party invitations to colourmatched houses. The experimenter explains to the child that there is only one direction they may travel in (i.e., it is a one-way road). The letters are to be placed in a pile in the back of the truck one on top of the other and that only the top envelope in the pile can be moved when making deliveries. One house is added with each level of difficulty making four levels of difficulty. As was demonstrated, in the Truck Loading task there is only one route to follow and children must plan how to distribute items in a reverse order, thus, this task has also been described as a reverse sequencing task (McCormack \& Atance, 2011). Essentially, this task requires participants to consider their route in advance rather than plan the route entirely.

To my knowledge, there are currently only two studies (Kamawar et al., 2019; Jerome et al., submitted) that have assessed planning in relation to saving with young 
children. The researchers (Kamawar et al., 2019; Jerome et al., submitted) argued that given children are both able to implement saving and are able to plan ahead, their saving behaviour may benefit from the opportunity to budget (i.e., create a savings plan). The researchers (Kamawar et al., 2019) found performance on the Truck Loading task to be significantly related to the number of marbles saved in the first trial, for only the budgeting condition. They interpreted this to mean that children with better planning skills benefitted from the opportunity to create a budget. They also found that children who planned to save one marble for their future self in the budgeting condition, were also more likely to indeed save at least one marble for themselves. This was only true for the budgeting condition. This supports the notion that spontaneous saving skills are still immature in the preschool years and may suggest that in order to plan effectively for the future, future saving goals and their potential outcomes need to be made more salient. Overall, these findings are consistent with Atance et al. (2017) in that encouraging children to self-project into the future (by either allowing them to create a budget, or illuminating their choices to spend or save), improved their saving ability.

Jerome et al. (submitted) also assessed planning in the same way as Kamawar et al. (2019). They first found that after controlling for age and language, performance on the Truck Loading task (Carlson et al., 2004) was not related to saving performance. These results are inconsistent with Kamawar et al. (2019) and given only one planning measure was used, more research using multiple planning measures may be warranted. Second, planning status was assessed in relation to saving status. The researcher found that planner status was a predictor of saving status using a logistic regression but notes 
that they had such a small number of non-planners and non-savers so their data was difficult to interpret.

Given I will be comparing data across these two tasks, it is important to describe some of the key differences between the methodology. While Kamawar et al. (2019) had children saving marbles (a resource itself) for future use, Jerome et al. (submitted) had children saving tokens (a symbol of a resource for future use). But, not only do these tasks differ in the nature of the resource, they differ in the nature of the reward. In Kamawar et al. (2019) children are given a fleeting reward. Once the marble goes down the run, there is no marble anymore, the enjoyment is finished, and the reward has now been consumed. In Jerome et al. (submitted), however, the reward is tangible and concrete, the child can play with toys as many times as they want and can enjoy the beauty of a sticker so long as they do not lose it! Whether saving for the future using a symbol of a resource or the resource itself changes children's performance has yet to be assessed, however previous research has shown that children display an advantage on some tasks when using symbols.

\section{The Potential Effect of Symbols on Saving Performance}

Symbols have been shown to improve children's performance on hot executive function (EF) tasks (Zelazo \& Carlson, 2012). The main difference between a hot EF task and a cool EF task is the degree of emotional involvement (Zelazo \& Carlson, 2012). Cool tasks are purely cognitive and have minimal affective components, such as planning, or working memory. Hot tasks assess affective decision making, in that a choice must be made under some emotional pressure, this includes inhibitory control 
tasks. Hot EF tasks have recently gained popularity with a general focus towards delay of gratification (Zelazo, Qu \& Kesek, 2010).

It has been shown that symbols allow increased psychological distance, this has been referred to in previous literature as symbolic distancing. Symbolic distancing lowers activation of the 'hot' impulsive system and allows room for the 'cool' cognitive system to take over (Carlson, David \& Leach, 2005). This has been shown to improve children's affective decision making (Carlson, David \& Leach, 2005).

The current research aims to assess performance differences on different types of savings tasks that either include a symbol of a resource to be saved, (i.e., tokens), or the resource itself, to be saved (i.e., a marble). It is likely children's abilities on tasks with an affective component will differ whether they are reasoning about a symbol of a resource or the resource itself due to symbolic distancing. It may be that children's saving or budgeting skills are improved by the psychological distance afforded by symbols.

While symbolic distancing may allow children to reason better about their decisions to budget and save, another principle may contribute to their spending behaviour. There may be a notable difference in how children may perceive spending whether the reward is fleeting or tangible. When spending the marbles themselves, the loss may be perceived as more salient, children must give in a marble, and although they get to enjoy the marble run, they do not instantly receive a tangible reward and what is concretely observed is simply the loss of the marble. When using tokens, however, spending a token would mean instantly receiving a tangible prize, versus children who are spending the marbles themselves. When children spend a marble in exchange for a 
reward, the initial pain of spending the marble may strip away from the enjoyment of getting to use it, making children more reluctant to spend.

This is similar to how adults behave when spending. Previous research in adults has demonstrated this via the Pain of Paying principle which was first described by Prelec and Loewenstein (1998). Prelac and Loewenstein (1998) explain that there is an inherent and immediate pain involved in making purchases, and that this pain can undermine the pleasure derived from the purchased product. Spending a token, on the other hand may attenuate the pain of spending a resource because the prize is vivid (the instant receipt of a prize). Based on this reasoning, it may be more challenging for children to spend a resource itself versus a symbol of a resource as the loss is more vivid. When spending the token, children lose a token but then receive a prize; but when spending a marble, the saliency of the reward is not as strong as the saliency of the loss.

Other adult research has also assessed how the spending behaviours in adults differ depending on mode of payment. Priya and Joydeep (2008) assessed the effects of payment form on adults' spending behaviour. They found that adults spend more when using a representation of money versus money itself. The researchers demonstrated that adults who were given $\$ 50$ in the form of scrip (scrip being a prepaid amount of money with the value indicated on the front), spent more than their counterparts who were given $\$ 50$ of cash.

Overall, it may be that children are able to budget better when reasoning about a symbol of a resource (due to increased psychological distance) but may end up spending more when using a symbol of a resource due to the Pain of Paying principle. The current thesis will investigate this possibility. 


\section{Current Study}

The current research aimed to examine performance differences on two savings tasks which differed in a number of ways, including whether children save the resource itself (i.e., marbles) or a symbol of a resource (i.e., tokens). I used the data from Kamawar et al., (2019) and Jerome et al., (submitted). I assessed five main research questions that will be described in more detail below, along with my hypotheses.

\section{Research Questions and Hypotheses}

There were five research questions and related hypotheses in the current study:

1. The first research question was: Will children spend more when using a resource or a symbol of that resource? I hypothesized that children would spend significantly more when using a symbol of a resource than the resource itself. This was predicted because when spending a resource itself, a loss may be perceived as more salient than when spending a symbol of a resource. Spending a symbol of a resource may allow for symbolic distancing and improve affective decision making, in this case, saving performance. Thus, spending a token would result in instantly receiving their reward, versus children in the Marble Study who spend the marbles themselves. The initial pain of spending the marble may strip away from the enjoyment of getting to use it. However, in the Token Study, receiving a prize despite having spent a token, on the other hand may attenuate the pain of having spent it.

To test this hypothesis, scores from the control conditions were compared across studies. 
2. The second research question was: Will children have more effective budgets using a symbol of a resource, or the resource itself? I hypothesized that children creating budgets using tokens would create more effective budgets relative to children using marbles. Number of resources budgeted for the more-preferred game, from the budgeting conditions in each study, were compared. Budgets were measured in two ways: number of resources saved for the preferred game, and a categorical label based on number of resources budgeted. This was based on a cut-off of three resources. Given that the data I used for the Token study (Jerome et al., submitted) resulted in a much greater proportion of planners than non-planners, it was challenging to use this as an indication of the quality of the budgets. It is difficult to define what the most effective budget is, while it may be beneficial to save all resources for the more-preferred game, it is equally reasonable to spend some of your resources in the least preferred game so as to avoid boredom. It may, however, be less reasonable to plan to spend more resources on a less-preferred game and save less resources for a more-preferred game. A cut-off score of three was selected to differentiate children who saved the majority of their resources from those who saved the minority of them. Using this logic, I divided the data categorically by strength' of the budget. A weak budget being one that allocated more resources to the first, and less-preferred game, while a strong budget one that allocated more resources to the second, and more-preferred game. 
3. The third research question was: Are children more likely to follow their budgets when the saving situation involves a symbolic representation of the resource relative to the resource itself? Scores from the budgeting conditions in each study were compared. I had predicted that children would be able to implement their budgets more appropriately when using a symbol than when using a resource. Symbols allow for increased psychological distance (in this case, symbolic distancing) and likely allows children to make better savings decisions. When given the opportunity to budget, I predicted that children in the token-based savings task would be more likely to accurately implement their budgets, without overspending, than would children in the marble-based savings task.

4. The fourth research question was: Will the relation between general planning ability (as measured by the Truck Loading task) and budgeting ability differ across the studies? The number of resources allocated for the preferred game from the budgeting conditions in each study and performance on the Truck Loading task were used for this analysis. I predicted there would be a significantly stronger correlation between planning and budgeting when in the token study than for the marble study (after controlling for age and language). The planning task used in both studies is the Truck Loading task, this task is a cognitive measure which does not include an affective component (as described above). Budgeting using tokens was expected to decrease the affective influence of the saving task, therefore, I expected budgeting in the token saving task would be more closely related to a cool EF task (like the 
Truck Loading task) than budgeting in the marble savings task. If this is the case, this would support the notion that symbols cool down the reasoning involved in budgeting and attenuated the affective influences of the task.

5. The fifth, and final, research question was: Does the relation between saving ability and age differ by study? Saving performance in the control conditions in each study were compared. I predicted saving ability would differ more between studies for younger children than between older children. No object can intrinsically serve as a representation, therefore the relation between a symbol and its referent (what it stands for) must be made clear in order to reason appropriately about the symbol. The need to represent rewards symbolically using a token will likely impede younger children more than older children. Previous research has found significant improvements in children's ability to reason about symbolic representations between ages four and five. For example, Bialystok et al. (2000) found that children's ability to reason about the arbitrariness of words and their referents improved significantly by age five. Zhou and Wang (2004) also investigated children's understanding of symbols. In this case, children were assessed on their ability to understand conventional number symbols. They found that children's ability to use numbers to represent small quantities was improved between 4and 5-years of age. Given children's understanding that money can be redeemed for other things is still emerging during the preschool years, I predicted that older children would have a better understanding of symbolic representations of value than their younger counterparts, alongside a stronger 
conception of symbols and their referents. Thus, I predicted that performance on the two studies, which include different types of resources, may make less of a difference to older children than it would for younger children.

\section{Methods}

\section{Token Saving Task (from Jerome et al., submitted)}

Participants. A total of 66 participants were recruited across the two conditions of interest for my study by Jerome et al. (submitted). Additional data was collected for another condition, but will not be included in my analyses. The control condition contained a sample of 35 , including 10 females. The participants in this group had a mean age of 56.23 months with a standard deviation of 7.57. The budgeting condition contained a sample of 31, including 15 females. The participants in this group had a mean age of 58.06 months and a standard deviation of 7.75. See Appendix A for task protocols.

Control condition. Participants were introduced to two games, the 'toy game', and the 'sticker game'. Each game was played on a different tray (green- and bluecoloured, respectively). On each tray was one bowl with 10 of the prizes relevant to that game (i.e., stickers or toys) and a small (colour-matched) sealed box slit from the top. This was the box the tokens were placed in. Participants were shown the prizes and asked to choose 5 of their favourite toys and 5 of their favourite stickers. These were placed in the appropriate colour-matched bowl. The experimenter then asked children if they preferred stickers or toys, the least preferred prize was placed in the first game while the more-preferred prize was placed in the second game. This was to give incentive to save. 
The experimenter then selected one toy and one sticker and added them to the appropriate bowls.

The following description will be an example of when a child had indicated their preference was stickers (the method was identical for toys, except that they would play the toy game second). Children were first presented with both trays. They were told they could use tokens to receive prizes, but once a token was spent, it could not be reused. The experimenter demonstrated this by buying the toy and sticker that they had placed in the prize bowls. They were then told they would be playing each game for three minutes and they may use their tokens in any game they choose, they were told: "We are going to be playing the toy game for three minutes, then we're going to be playing the sticker game for three minutes. You can spend your tokens in the toy game or you can spend your tokens in the sticker game. Let's start with the toy game." This was to show them that they had the choice to spend in either game, but while not influencing their choices by using the word 'save'. Children were asked comprehension check questions to make sure that they understood the rules of the games, and corrective feedback was provided as necessary.

The experimenter then placed the green tray (toy game) in front of the child and told them they were going to do some work until the timer rang. The experimenter next set a timer for three minutes then pretended to do paperwork beside them (on a clipboard). After three minutes, the experimenter told the participant they were done playing the 'toy game' and would now play the 'sticker game' for three minutes. The experimenter put away the green tray and brought out the blue tray. They told the participant they were going to do some work for three more minutes. The experimenter 
then documented the number of tokens saved for the 'sticker game'. Children were coded as savers if they saved at least one token for the 'sticker game'. Children were allowed to keep all stickers at the end of the testing session (given to the classroom teacher in an opaque envelope with the child's name to take home).

Budgeting Condition. The experimenter showed participants both trays. Two small baskets were included in this part of the study, one corresponding in colour to each tray. Each basket was placed in front of its matching tray. Five tokens were placed in a line in front of the participants. The participant was then told they would only get five tokens and they must decide the number tokens they would like to use for each game. They were then told to place the tokens they would like to use for each game, into the corresponding basket. After this, trials began (with the less-preferred game first). The measure of interest were the participants' budgets and their actual saving performance. Children who saved at least one token for their more-preferred game were coded as 'savers'. Further, children were scored as 'planners' if they planned to save at least one token for their more-preferred game.

\section{Marble Saving Task (from Kamawar et al., 2019)}

Participants. A total of 54 participants completed this study. Participants were randomly assigned to either the control condition or the budgeting condition. The control condition contained a sample size of 25 . The sample consisted of 15 girls with the mean age being 54.2 months. The budgeting condition contained a sample size of 29 . The sample included 16 females with the mean age being 53.7 months. See Appendix B for full task protocol. 
Control condition. Before beginning the savings trials, children were familiarized with two rooms: the blue room (containing a large marble run) and the red room (containing a small marble run). Children first visited one of the rooms and were shown that a marble could only go down the run once. They were given a demonstration to show how the marble went into a closed box at the end of the run and could not be used again. Children were given the opportunity to try both marble runs prior to testing and asked which run they preferred - this run was to appear in the second game to have an incentive to save. This was then repeated in the next room. Then the trials began. The experimenter explained to the child that they would be staying in one of the rooms for three minutes and they would next be staying in the other one (the order of the room varied depending on the child's preference indicated at the beginning of the study).

They were then given five one-time-use marbles, told they may spend them in either game as they please, and then taken to their first room. In order to keep their interactions with the child to a minimum, the experimenter told the child that they were going to do some work until the timer rang. After the three minutes were up, the child, along with any marbles they had saved, were moved to the next room for three minutes. The researcher then indicated that she 'found' five more marbles, and the entire procedure was repeated. However, for the purposes of this study, Trial 2 data will not be included. The researcher recorded the number of marbles children saved for the second room. Children were also coded as savers if they saved at least one marble for the second room.

Budgeting Condition. In the budgeting condition, participants were given a small tray containing two bowls. Propped behind each was a photo of one of the marble runs. 
Children were told they could decide the number of marbles they wanted to use in each room by putting the amount of marbles they wished to use in the corresponding bowls. The researchers avoided words like 'save' or 'plan' and did not give any feedback on children's budget. Children were then taken to the room with their less-preferred marble run, followed by the room with their more-preferred one, each for 3 minutes. Children took both bowls with them to each room. The same procedure was repeated for a second trial with five new marbles. Children were also labelled as 'planners' if they planned to save at least one marble for their preferred run.

\section{Planning Measures}

Truck Loading. This task is a measure of general planning ability. Refer to protocol indicated in literature review on p, 21. Children's scores on this measure ranged from 0 to 5 and were used in the analyses. See Appendix C for full task protocol.

\section{Control Measures}

Language Control. An abbreviated version of the Peabody Picture Vocabulary Test (third edition; PPVT-III) will be used as a measure of general language ability. Initially, children shown a 4-photo grid and are sequentially read a list of words. They are told to point to the photo that corresponds with each word. With each subsequent word children are shown a new set of photos to choose from. Each set consists of 10 words and the task ends when children make 8 or more errors on a single trial. This abbreviated version of the task begins at set 3 (which is where the expected performance of typically developing 5-year-olds to be) and finishes at set 11. Raw scores were used in the analyses. 


\section{Results}

\section{Preliminary Analyses}

An alpha of .05 was used for all statistical analyses. The descriptive statistics for both studies are displayed in Tables 1 and 2. Preliminary analyses were conducted prior to examining performance on the savings task to determine whether the participants were matched across all four conditions (displayed in Table 3). An analysis of variance was conducted to test for any significant differences across the studies, and the conditions, in terms of the participants' ages (in months), planning ability (as measured by the Truck Loading task), and their general language ability (as measured by the PPVT-III). Results revealed a significant between-study differences on age. A normal Q-Q plot (split by study) indicated four outliers in the data (41 months $n=1$, from Jerome et al., submitted, and 75 months $n=1$ and 76 months $n=2$, from Kamawar et al., 2019). Therefore, these participants were removed from the final analyses. The normal Q-Q plot (figure 1) and detrended normal Q-Q plot (figure 2) can be found in Appendices D and E, respectively. The final sample size was $\mathrm{N}=116$; with $\mathrm{n}=63$ from Jerome et al. (submitted) and $\mathrm{n}=53$ from Kamawar et al. (2019). The age effect between studies was no longer significant after the removal of these outliers; therefore, none of the listed factors needed to be controlled in the subsequent analyses.

Table 1

Means and Standard Deviations by Study

Token study (Jerome et Marble study (Kamawar et al.,

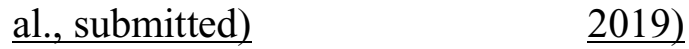

Mean $\quad$ SD $\quad$ Mean $\quad$ SD




\begin{tabular}{lcccc}
\hline Age (in months) & 56.21 & 6.63 & 54.13 & 8.46 \\
Resources Saved & 1.84 & 1.77 & 1.60 & 1.68 \\
(out of 5) & & & & \\
Planning (max of & & 1.25 & 2.67 & 1.55 \\
4) & 2.79 & & & \\
& & & & \\
PPVT-III (raw) & 73.57 & 13.06 & 72.28 & \\
\hline
\end{tabular}

Table 2

Means and Standard Deviations by Condition by Condition

Token study (Jerome et al., $\quad$ Marble study (Kamawar et al., 2019) $\underline{\text { submitted) }}$

\begin{tabular}{|c|c|c|c|c|c|c|c|c|}
\hline & \multicolumn{2}{|c|}{ Control } & \multicolumn{2}{|c|}{ Budgeting } & \multicolumn{2}{|c|}{ Control } & \multicolumn{2}{|c|}{ Budgeting } \\
\hline & Mean & SD & Mean & SD & Mean & SD & Mean & SD \\
\hline Age (in & 55.68 & 6.93 & 56.83 & 6.31 & 54.71 & 8.37 & 53.66 & 8.65 \\
\hline \multicolumn{9}{|l|}{ months) } \\
\hline Resources & 1.24 & 1.84 & 2.55 & 1.40 & 1.00 & 1.38 & 2.10 & 1.76 \\
\hline \multicolumn{9}{|l|}{ Saved } \\
\hline (out of 5) & & & & & & & & \\
\hline Planning & 2.71 & 1.24 & 2.90 & 1.26 & 3.04 & 1.38 & 2.37 & 1.57 \\
\hline
\end{tabular}


$\begin{array}{lllllllll}\text { PPVT-III } & 71.03 & 13.91 & 76.55 & 11.53 & 75.67 & 16.87 & 69.50 & 21.07\end{array}$ (raw)

Table 3

Analysis of Between-Group Differences on Age, Planning and Language

\begin{tabular}{lcccc}
\hline & \multicolumn{2}{c}{ Condition } & \multicolumn{2}{l}{ Study } \\
Measure & $\mathrm{F}$ & $\mathrm{p}$ & $\mathrm{F}$ & $\mathrm{p}$ \\
\hline Age (in & .001 & .981 & 2.19 & .142 \\
months) & & & & \\
Truck & .565 & .454 & .207 & .650 \\
Loading & & & & \\
PPVT & .079 & .779 & .165 & .685 \\
\hline
\end{tabular}

\section{Hypothesis 1}

Two analyses assessed my first hypothesis that children in the Control condition would save less for their more-preferred game in the Marble study than they would in Token study: a one-way analysis of variance (ANOVA) and Chi-square analysis. The assumption of normality was violated as the outcome variable (in this case the number of resources saved) was positively skewed. For this, a Poisson analysis was suggested. Given the overdispersion, I opted for a negative binomial loglinear regression to assess this hypothesis. This analysis estimates a distribution with a variance equal to the mean and then corrects for overdispersion by including a dispersion parameter. This parameter was estimated in my analysis (not fixed). The data was split by condition and saving 
performance in the two control groups (across studies) was compared. In the control condition, after controlling for age in months, children saved 1.24 times more resources in the Token study than in the Marble study, but this value was found to be not significant $(p=.670)^{1}$. Contrary to my hypothesis, participants in the Token study did not save significantly more resources compared to participants in the Marble study.

A Chi-square analysis was also conducted to assess the same hypothesis, using categorized performance. A new dichotomous variable was created to indicate saver strength. Participants who saved more resources for their more-preferred game than they spent in their less-preferred game were classified as strong savers while those who saved fewer resources for their more-preferred game and spent more on their less-preferred game, were classified as weak savers. Therefore, if the number of resources saved for the second game was 3 or more, the participant was categorized as a strong saver, if the number of resources saved for the second game was less than 3 , the participant was categorized as a weak saver. A Chi-square analysis was conducted to assess the proportion of strong and weak savers across both studies in the control condition. Within the two Control conditions, 69 children were weak savers, and 47 children were strong savers. All of the Chi-square assumptions were satisfied. The results indicated that there was no significant difference in the proportion of strong and weak savers between the Token study and Marble study in the control condition. $\mathrm{X}^{2}(1, \mathrm{~N}=58)=.404, \mathrm{p}=.525$.

\footnotetext{
${ }^{1}$ The exponential beta value can be interpreted as an effect size and is typically what is reported for a negative binomial regression (Leth-Steenson, Dec. 22, 2020, personal communication)
} 
Table 4

Number of Strong and Weak Savers by Study

Token study (Jerome et al., $\quad$ Marble study (Kamawar et

$\underline{\text { submitted; } \mathrm{n}=63) \quad \text { al., 2019; } \mathrm{n}=53 \text { ) }}$

\begin{tabular}{llll}
\hline Strong & 28 & Strong & 19 \\
Weak & 35 & Weak & 34 \\
\hline
\end{tabular}

\section{Hypothesis 2}

A Chi-square analysis was conducted to assess my second hypothesis which was that children in the Token study would be better planners, relative to children in the Marble study. To test for this, a new dichotomous variable was created to indicate planner strength. Participants who planned to save more resources for their morepreferred game than they spent in their less-preferred game were classified as strong planners while those who planned to save fewer resources for their more-preferred game and planned to spend more on their less-preferred game were classified as weak planners. Therefore, if the number of resources budgeted for the second game was 3 or more, the participant was a strong planner, if this was less than 3 , the participant was a weak planner. A Chi-square analysis was conducted to assess the proportion of strong and weak planners across both studies in the budgeting condition. Within the two budgeting conditions, 35 children were weak planners, and 23 children were strong planners. All of the Chi-square assumptions were satisfied. The results indicated that the difference in the proportion of strong and weak savers between the Token study and Marble study in the control condition approached significance, $\mathrm{X}^{2}(1, \mathrm{~N}=58)=3.52, \mathrm{p}=.060$, suggesting 
some support for this hypothesis with a greater proportion of strong savers in the Token study.

Table 5

Number of Strong and Weak Planners by Study

\begin{tabular}{lclc}
\multicolumn{2}{l}{\begin{tabular}{l} 
Token study (Jerome et al., \\
\multicolumn{2}{r}{ submitted; $\mathrm{n}=34)$}
\end{tabular}} & \multicolumn{2}{l}{ Marble study (Kamawar } \\
Strong & 21 & Strong & 14 \\
Weak & 8 & Weak & 15 \\
\hline
\end{tabular}

A negative binomial regression was also used to assess this hypothesis. Age was entered into the regression as a control and the relation between the number of resources budgeted and study was assessed. It was found that children budgeted 1.38 times more resources in the Token study than in the Marble study. This relation approached significance as well $(\mathrm{p}=.064)$.

\section{Hypothesis 3}

An analysis of variance (ANOVA) was conducted to assess my third hypothesis that children will better implement their budgets in the Token study (Jerome et al., submitted) relative to the Marble study (Kamawar et al., 2019). A deviation score, which is the number of resources budgeted subtracted from the number of resources actually saved, was the dependent measure used to assess this hypothesis. Each of the main ANOVA assumptions were satisfied. The independent variable was study (whether Token or Marble) and the dependent variable was the deviation score. Results indicated a non-significant effect $F(1,56)=.644, p=.426$. Contrary to my hypothesis, participants 
in the Token study did not implement their budgets significantly better than those in the Marble study.

\section{Hypothesis 4}

For this hypothesis I predicted that the relation between general planning ability and budgeting would be stronger in the Token study than in the Marble study. More specifically, the hypothesis was that a relation between budgeting scores and performance on the Truck Loading task was moderated by study (whether Token or Marble) with relation being stronger for the Token study. The outcome variable for budgeting performance was found to violate the assumption of normality and so a negative binomial regression was used to assess this hypothesis instead of the planned ANOVA. Both the main effects of general planning ability and study (whether Token or Marble) on budgeting ability were assessed alongside the interaction effect of general planning and study. Given that age significantly predicted budgeting scores, age (in months) was included in the model and controlled for. The effect of the interaction between planning and study on budgeting had a magnitude of 1.090 and was found to be not significant ( $p$ $=.079)^{2}$. The relation, therefore, between planning and budgeting remained similar regardless of study (whether Token or Marble) which was not in support of my hypothesis.

\section{Hypothesis 5}

My final hypothesis was that the relation between saving ability and age would differ as a factor of study. The outcome variable, which was the number of tokens saved,

\footnotetext{
${ }^{2}$ The exponential beta (i.e. exp(b)) value can be interpreted as an effect size of magnitude and is typically what is reported for a negative binomial regression (Leth-Steenson, Dec. 22, 2020, personal communication).
} 
was not found to be normally distributed. For that, a negative binomial regression was chosen for this analysis as it is optimal for skewed data. The main effects of age (in months) and study were also included in the model. However, given the main effect of study on saving was already assessed in Hypothesis 1 the focus of this analyses was only on the influence of interaction of age and study on number of resources saved. This effect of the interaction between age and study on the number of resources saved had a magnitude of 1.002 and was found to be not significant $(p=.591)^{2}$. The relation between the number of tokens and age did not differ as a factor of study. This means that older children did not demonstrate better saving with tokens relative to the younger children, with this (lack of) effect being constant across the two studies.

\section{Discussion}

The goal of the present study was to compare children's performance on two types of savings tasks which differ in a number of ways. One notable difference has to do with the resource to be saved; while one requires children to save the resource itself (data from Kamawar et al., 2019), the other requires them to save a symbol of a resource (using data from Jerome et al., submitted). I will discuss each of my hypotheses, and the relevant results, in turn.

The primary research question was whether ability to save a limited resource differed across the two types of savings tasks. To address this goal, children's saving performance was compared across the two studies, for the control conditions. I predicted that children would spend more in the control condition, on the less-preferred game, when using tokens due to the attenuated pain of spending a symbol of a resource over a resource itself. Overall, there was no support for my hypothesis. The initial pain of 
spending the marble itself did not appear to impact spending behaviour and children did not spend less marbles, as predicted. Although more resources were saved in the Token study than the Marble study (an average of 1.84 and 1.60 resources, respectively), there were no significant differences in the number of resources saved between the control conditions from each study.

My null findings may have been due to a handful of reasons, mostly related to the fact that these studies were not designed to be contrasted, thus the number of resources actually saved may have been influenced by a multitude of factors. Notably, these two studies differ in more ways than just the type of resource, which was non-symbolic in the case of the marbles, and symbolic in the case of the tokens. They also differed in terms of type of reward: experience versus a material reward. We can see the marble as a form of payment for the experience of using the marble run, in that regard it could be considered payment for an experience, the experience of using the marble run that is, rather than a reward in and of itself. In the Token task, however, the reward consisted of a toy or a sticker, both being material items. It is interesting to see that despite these differences saving performance remained relatively stable across both studies, suggesting that saving ability in preschoolers may be more robust than expected. Future work should address this by comparing the two types of resources more directly, without the confounding nature of the rewards. I suggest future studies include a task where children redeem the same type of reward across conditions. For example, the following protocol was inspired by Chernyak, Leech \& Rowe (2017)'s 'saving for the future' task: In this task children are given stickers that they can use now, by sticking them on a white sheet of paper, or use later, but sticking them onto an appealing dinosaur scene. A potential future protocol 
to assess saving behaviour could include a similar type of reward. One condition could include tokens to be redeemed for stickers; in this, children would budget and spend/save tokens on stickers to be used in either game (with the first game including a lesspreferred scene to put the stickers, while the second game included a more-preferred scene to put the stickers). In the other condition, children could create budgets using the stickers themselves and then later choose to spend them in either the first game (i.e., by sticking them onto the less-preferred scene) or spend them in the second game (i.e., by sticking them onto the more-preferred scene). In this, both conditions include the same rewarding experience of sticking stickers onto a scene and we may be better able to infer the influence of using a symbol to represent a resource.

The second hypothesis focused on children's ability to budget for their future selves, comparing performance across the budgeting condition from each study. To address this question, the average number of resources budgeted for the preferred game was compared. Further, children's budgets were classified by strength (i.e., whether the majority or minority of resources were saved) and compared across studies. Specifically, children were classified as strong planners if they budgeted more than half of the resources for their more-preferred game and weak planners if they budgeted fewer than half of resources for their more-preferred game. There was marginal support for this hypothesis with the number of resources planned to save as the outcome variable in a negative binomial regression. These scores were compared across studies and the difference between the proportion of weak and strong planners across the two studies approached significance. 
Though only marginal, this finding warrants some cautious interpretation. Children's budgeting performance in the token study may have been better due to the psychological distance afforded by symbols. This presumption rests on previous research which suggests that symbols allow increased psychological distance, referred to as symbolic distancing. Thereby lowering activation of the 'hot' impulsive system allowing room for the 'cool' cognitive system to take over (Carlson, David \& Leach, 2005). This suggests that although ability to actively save appears to be robust across studies, the ability to create a saving plan that favours a preferred game may be better when using a symbol of a resource.

Although this result was not found to be significant, it is important to consider what the necessary conditions would have been for this result to be found significant. Children in the Marble study saved an average of 2.1 marbles for their more-preferred game, while children in the Token study saved an average of 2.55 tokens for their morepreferred game (see Table 1). Although this difference trends in the predicted direction, it only approached significance. In order for the difference between the two conditions to be significant, children would either have had to save more than an average of 2.55 tokens (in the Token study) or less than an average of 2.1 marbles (in the Marble study) for their more-preferred game. However, it may not be likely that children will save more than three resources, because it is not advantageous to do so.

Thus, what is the ideal number of resources to save and budget? It is not unreasonable to allocate some resources to the current game and some to a future game, even if the current game is less appealing. Is it inherently better to budget four resources for the future than it is to budget three? Or is it inherently worse to budget one marble for 
the future as opposed to budgeting two? In fact, the modal number of resources saved for both studies is three. In the Marble study, $24.5 \%$ of all participants chose to save three resources for their more-preferred game and $44.8 \%$ of all children who saved at least one resource, chose to save three. These values were relatively similar in the Token study (23.8\% and $41.7 \%$, respectively). Children may have decided a $2: 3$ savings pattern was the most advantageous choice in such a savings task where one should ideally make use of their time in both the first and second game. This suggests that this budgeting strategy may be robust to the overt differences between these two tasks.

The third hypothesis focused on whether children's ability to implement their budgets varied across studies. To address this, children's deviation scores were compared across studies (for the budgeting condition). The deviation score is the difference between the number of resources planned to save and the number of resources actually saved. There was no support for my hypothesis that children would better implement their budgets in the Token study than the Marble study, which was expected because of the symbolic distancing afforded by the Token task and the pain of paying principle relevant to the Marble task. The lack of effect may have been due to other task specific factors; namely, the difference in timing related to the 'consumption' of the reward.

It is important to note that in the Marble study, children first created a savings plan with Marbles and then later were given the option to 'spend' the Marbles (which would be done one by one). In this task, the resource is spent throughout the 3-minute game and the reward is experienced throughout that time frame. In contrast, in the Token study, children are given their reward during the game (i.e., the toy prize) after spending a token but cannot play with or use the toy until after the game has finished. Children 
were allowed to keep their prizes at the end of the session and their prizes were placed in an opaque envelope and given to their classroom teacher to take home.

This qualitative difference between both studies is notable as it makes it challenging to interpret children's ability to implement their budgets. This may be because the tangibility of the reward possibly has a stronger influence on children's saving behaviours when the reward is received throughout the game as opposed to after the game. In other words, the pain of paying (in the Marble study) may have been amplified after children had already experienced the fleetingness of the reward. Thus, because budgets were made prior to the actual receipt of the reward, it is likely here that children's performance was also influenced by the tangibility of the reward. Earlier I discuss differences in type of reward, either experience or material, and how these rewards are in turn perceived differently. This is not the only way the rewards differ as they also differ in terms of their tangibility (i.e., fleeting or lasting). A fleeting reward cannot be reused once it has been used up, while a lasting reward can be kept indefinitely. A food item is an example of a tangible fleeting reward, as once it is eaten it cannot be eaten again. This is different from a toy, for example. Although both are material, the toy can be used as many times as one wishes, however, once a food item is 'used', it cannot be used again. Experiencing the reward throughout the game as in the Marble task may have made children more reluctant to spend the subsequent Marbles and may have been the cause for this null finding (i.e., that children did not implement their budgets differently across studies).

Another potential reason that children's deviation scores may not have differed by study is because both studies were designed in such a way that children's budgets were 
relatively salient to them throughout the task. In both studies, children's savings plans were created by allocating the desired number of resources to the appropriate bowls. These bowls were kept with the children throughout the task to give them the option to follow their savings plan or deviate from it. This, however, may have served as a visual cue that they had created a savings plan and may have allowed them to be more mindful of their spending. It is possible that the visual cues were impactful enough on children's saving such that the type of resource had little influence on children's ability to implement the budget, thereby resulting in very similar deviation scores across studies. A subsequent one sample t-test to see if the deviation scores from each study differed from zero revealed that in both studies the deviation score did not differ from zero (Marble study, $\mathrm{p}=.806$; Token study, $\mathrm{p}=.100)$, indicating that children implemented their budgets quite well in both studies, without a significant difference between the two. As mentioned above, having a visual cue may have alleviated some of the difficulties around saving, thus minimizing the effects of symbolism in relation to the research. A future study could address this by having children place their budgets in another area adjacent to the participant to refer to when needed, rather than immediately in front of them. In this way, while they continue to have access to the budget (as would an adult in the real world), their budget is not constantly in view for the duration of the task thus reducing its saliency.

I found no support for my fourth hypothesis that the relation between children's performance on the planning task and their strength of budget would differ by study (Token vs. Marble study). This finding is not in line with the expectation that performance on 'cool' cognitive tasks may be more closely related to performance on 
other 'cool' cognitive tasks. Previous research shows a distinction between performance on 'cool' cognitive tasks versus 'hot' cognitive tasks, with the main differentiating factor being the degree of affective involvement (Carlson, David \& Leach, 2005). 'Cool' cognitive tasks have reduced affective components and it was suggested that 'cool' tasks would be more related to performance using a resource that reduces affective components of a task (i.e., a symbolic resource), in this case, a token. Therefore, given the Truck Loading task is a 'cool' cognitive task, and the Token saving task includes symbolic resources (which have been shown to reduce the affective components of tasks), it was expected that Truck Loading scores and the number of resources budgeted for the morepreferred game be more closely related in the Token study relative to the Marble study.

General planning, however, was not found to be more closely related to budgeting in the Token task versus budgeting in the Marble task. It is possible that despite the use of tokens potentially alleviating some of the effects of affective decision making, it does not remove these challenges entirely. These results are nonetheless informative, mainly given they demonstrate that children may have been more emotionally invested in the prizes in the Token study than presumed, making this task 'hotter' than expected, in which case these null findings would be more consistent with previous research.

The final research question asked whether the relation between saving performance and age would differ as a factor of study. This was expected because older children may have more experience using money as a form of payment and this may have minimized the benefits of symbolic distancing from using the tokens. There was no support for this hypothesis. This suggests that children's ability to perform on the two savings tasks did not differ as a factor of how old the participants were. This result was to 
be expected after no differences were found in saving performance between both studies (i.e., after the results of hypothesis one).

Other future-oriented cognitive behaviours emerge in the preschool years and tend to improve with age. For example, one study (Caza \& Atance, 2018) found that 4- and 5year-olds spontaneous talk about the future was significantly higher than 3-year-olds. In another study (Russell, Alexis \& Clayton, 2010), 5-year-old children were able to accurately select a necessary item for future use at a rate significantly higher than 3- and 4-year-olds. Thus, given saving is a future-oriented cognition, previous research would suggest that it likely improves with age. However, this may not be the case in the age range tested in these two studies. Previous research, including similar age groups, demonstrates mixed findings (described in more detail in the introduction; refer to $p, 4$ ) in the relation between age and saving behaviour. While some studies have not found a relation between saving and age (Metcalf \& Atance, 2011; Kamawar et al., 2019), other research has found that saving improves with age (Atance, Metcalf \& Theissen, 2017; Dueck et al., 2019). Notably, the studies that have found age effects also included a prompt in their procedure. It could be that children's saving ability does not demonstrate variability until a later age, or it could be that a prompt has facilitated children's ability to reason about saving and has in turn, allowed for more variability. The widest age range assessed in previous research was by Dueck et al., (2019) who assessed children from 3to 7-years and were able to find age effects. Their saving paradigm, however, included a prompt (as mentioned above) it is therefore not clear whether we would have observed improved saving ability within that age range if a prompt was not present. Thus, in order to assess children's progression of spontaneous saving behaviour it may be beneficial for 
future research to include older children such as 7- and 8-year-olds while taking into consideration the impact of a verbal prompt.

It is also important to note that these studies were not designed to be compared and contrasted, thus they are not perfectly matched comparisons. This is a relevant limitation of this thesis and will be described in more detail in the limitations section below.

\section{Additional Considerations}

Beyond the interpretations directly related to the hypotheses, other aspects of the studies and the findings warrant some discussion. First, given that participants have to reason about specific quantities ranging from zero to five in the savings tasks, children who have better numerical skills may demonstrate superior budgeting and savings skills. Therefore, it may be useful to investigate individual differences in number sense. It may be that children with a more developed number sense create better budgets or save better for their more-preferred game than children with less developed number sense. A number sense skill that may be beneficial to assess is cardinality (i.e., the principle that the last number you count in a set, is the number of items that are in said set; Fuson, 1992). Thus, future studies should employ a measure of children's number sense to determine whether it is predictive of their saving and budgeting performance.

Another factor to be taken into consideration is children's appraisal of value of each of the two rewards (in the less-preferred game and the more-preferred game). The present savings tasks create a state of internal conflict within children where they must decide if they would like a less desirable reward immediately or a more desirable reward later. For this, it is important to consider the nature of these two rewards and how that 
may have an influence on children's spending patterns. The challenge of saving is accepting a cost in the present in exchange for a benefit in the future. Children, therefore, need to make an appraisal of value and dictate how they wish to proceed to maximize benefit. If this appraisal is easily made, or too challenging to make, it may impact how children choose to save. One example where an appraisal of value may have been increasingly challenging to make is having children choose between stickers and toys, as done in one of the studies used in the current thesis (Jerome et al., submitted). Here, children are asked to decide if they like toys more, or stickers more, and it is possible that in their day-to-day life they prefer one over the other, but in this direct context the stickers available (or the toys available) were not as appealing. This dilemma possibly makes it difficult for children to choose their 'favourite item'. In the Marble study, an important factor is that both the current and future items are the same type of reward, but just larger and smaller versions (i.e., quantitively different), and this may make it easier to judge value. One does not need to decide whether they like marble runs or not, but rather if they would like a larger or smaller one. However, in the Token study, the rewards for the first and second game differ not just quantitatively, but qualitatively. This may make it challenging for children to compare the relative values of the immediate and delayed rewards. Future research could also benefit from taking these value judgments into account.

As mentioned above, children must make an appraisal of value of both rewards and then subsequently decide how they would like to save. If a child found the second game to be almost as rewarding as the first, then it would be unreasonable to spend all resources in the second game. Or, if a child decided the second game was much more 
appealing than the first, than it would be unreasonable to spend most resources on the first game. For example, in Dueck et al. (2019) raisins and Smarties were used. If not having any raisins in the present is not interpreted to be costly relative to the benefit of eating Smarties in the future, then the incentive to save will be much greater. That being said, it was found that in Dueck et al., (2019) even young children (3-year-olds) were more inclined to save than spend - which was contrary to previous findings where the majority of 3-year-olds did not choose to save. Therefore, in order better assess children's budgeting and saving performance, it is important to also explicitly consider the degree to which they prefer the prizes (i.e., how much they like each of the 'games').

In the current study, it is impossible to infer child preference from the data; I, therefore, suggest including a measure of preference in subsequent studies, with the following protocol as an example: Children rate their preference for both the first and second game on a child-friendly Likert scale using a happy face, a neutral face and a sad face. These scores would be ranked from one to three (sad to happy, relatively) and the difference between preference for the second game over the first would be calculated by subtraction (for example, if the second game is rated a happy face, it is given a score of three, if the second game is rated a neutral face, it is given a score of two, the difference score therefore equals $3-2=1$ ). This protocol would allow researchers to investigate whether the magnitude of difference in preference relates to the likelihood to save. That being said, if children consider both games almost equally appealing, they may choose to spend more in the current game.

Earlier I raised the question of what the ideal savings plan may be. I argue that an ideal plan is one that results in saving a greater number of resources for the more- 
preferred game relative to the less-preferred game. It appears the most popular response for children who had chosen to save at least one resource for the future was in fact three resources. In other words, more children allocated three resources to their more-preferred game and two resources to their least preferred game than any other saving pattern. Notably, no previous research on saving has included the use of an even number of resources (all previous research on saving has included either three resources or five resources), ergo the option to allocate half of the resources to each game was not available. In order to deduce what children's ideal saving plan is, it may be beneficial to include all possible options of saving patterns. Spending half your resources now and saving the other half for later is a completely viable saving pattern and it would be interesting to see if, given the option to allocate the same number of resources to each game, would children have chosen to save differently. This may allow us to more accurately conclude what the most popular or ideal savings plan is for children.

\section{Limitations}

There are a number of limitations that require discussion. One notable limitation for the current thesis is that it may be possible that my sample size was too small to capture any effects. Therefore, it may be that an effect of study truly does exist but this study was unable to detect it. It is worth noting that the effect sizes found for hypotheses four and five were relatively small (close to 1) and a larger sample size is likely needed to capture an effect if there exists one.

Another limitation, discussed earlier, is that the two studies being compared differ not only in terms of type of resource (symbolic vs. non-symbolic) but also differ in terms of tangibility of the reward (fleeting vs. lasting) and the nature of the reward (experience 
vs. material). In the Token task the rewards are stickers or toys, these rewards are both lasting and material. In the Marble task the reward is a marble to use with the marble run, this reward is thus fleeting and an experience. I discuss the potential influences of tangibility of the reward with hypothesis 3 (refer to $\mathrm{p}, 38$ ).

In terms of the nature of the reward, this also an important factor to consider because research in adults has demonstrated that people do not perceive experiential rewards and material rewards in the same way (Carter \& Gilwich, 2010). It appears adults are typically less comparative when evaluating experiential rewards and are in turn more satisfied with experiences than material rewards (Carter \& Gilwich, 2010). Other research shows adults are happier when spending money on experiences than material goods (Caprariello, Peter and Reis, 2013). Given that the Marble study includes an experiential reward while the Token study includes a tangible reward, it is challenging to interpret performance across the two studies, the Marble study may have been more motivating in some ways relative to the Token task given the reward was an experience rather than a material item.

The combined effects of tangibility of the reward, the type of the reward, and the type of resource could all have contributed to saving performance and using existing data from previous savings studies (Kamawar et al., 2019 and Jerome et al., submitted) makes it impossible to tease these apart. These limitations, thus, hinder the ability to interpret these null results and further research is warranted. It is therefore crucial that future studies are matched in order to allow for more accurate comparisons.

Another difference between the two tasks has to do with the elapsed time between 'spending the resource' and 'receiving the purchase'. In the token savings task, children 
redeem tokens for prizes during the task, but cannot interact with their prizes until after the task is finished. This was made to prevent children from distracting themselves by playing with the first reward, thereby potentially making waiting for the preferred game easier. However, it had the unintended effect of impacting the time lapse between spending and receiving. In the Marble run task, children are to redeem a marble for the desirable experience of playing with the Marble run, in this case children instantly receive the reward. Children in the marble savings task receive their 'reward' throughout the game and this, in turn, may have had an influence in how children chose to spend their remaining resources. It may have been more, or less, challenging to adhere to their budgeting plans whether they have experienced the reward already or are anticipating its receipt at the end of the game (as in the Token savings task). Saving and spending are transactional and future studies should take this into account. Receiving a reward shortly after giving up a resource is more akin to saving and spending in the adult world, and so when designing savings tasks, it may be more beneficial to allow children to receive their rewards immediately (or shortly after) spending a resource.

\section{Conclusion}

In sum, it was found that saving performance was fairly consistent across both studies. While this could suggest that type of resource to be saved does not influence saving behaviour, it is important to consider that these studies differed in more than just type of resource. In terms of budgeting performance, children tended to, in absolute terms, budget more resources for their more-preferred game in the Token task than in the Marble task, and there tended to be more strong planners in the Token task than the 
Marble task. Although these results were not significant, they may suggest there may be more to explore here in future work.

Overall, it is impossible to draw any strong conclusions regarding children's performance on these different types of saving tasks given the number of differences between them, as these tasks were not designed to be directly compared and contrasted. It may very well be that children's performance on a saving task is not facilitated by the psychological distance afforded by symbols or impeded by the pain of paying principle, but it is also possible that other variables have contributed to these null results. Future research should, therefore, carefully and systematically contrast other factors that may affect saving performance, including: the type of resource (a symbol of a resource vs. a resource itself), the type of reward (experiential vs. material), and the tangibility of the reward (tangible vs. fleeting). In sum, although the conclusions that can be drawn from this research should be interpreted cautiously, given the multiple differences between these two studies that have been compared, the results of this research provide direction for future research designs. 


\section{References}

Atance, C. M., \& O'Neill, D. K. (2001). Episodic future thinking. Trends in cognitive sciences, 5(12), 533-539.

Atance, C. M., Metcalf, J. L., \& Thiessen, A. J. (2017). How can we help children save? Tell them they can (if they want to). Cognitive Development, 43, 67-79.

Baddeley, A. D., \& Hitch, G. (1974). Working memory. In Psychology of learning and motivation (Vol. 8, pp. 47-89). Academic press.

Belanger, G., Boudjema, F., Pukhov, A., \& Semenov, A. (2014).micrOMEGAs_3: A program for calculating dark matter observables. Computer Physics Communications, 185(3), 960-985.

Bialystok, E. (2000). Symbolic representation across domains in preschool children. Journal of experimental child psychology, 76(3), 173-189.

Bull, R., Espy, K. A., \& Senn, T. E. (2004). A comparison of performance on the Towers of London and Hanoi in young children. Journal of Child Psychology and Psychiatry, 45(4), 743-754.

Canfield, R. L., Smith, E. G., Brezsnyak, M. P., Snow, K. L., Aslin, R. N., Haith, M. M., ... \& Adler, S. A. (1997). Information processing through the first year of life: A longitudinal study using the visual expectation paradigm. Monographs of the society for research in child development, i-160.

Caprariello, P. A., \& Reis, H. T. (2013). To do, to have, or to share? Valuing experiences over material possessions depends on the involvement of others. Journal of personality and social psychology, 104(2), 199. 
Carlson, S. M., Moses, L. J., \& Claxton, L. J. (2004). Individual differences in executive functioning and theory of mind: An investigation of inhibitory control and planning ability. Journal of experimental child psychology, 87(4), 299-319.

Caza, J. S., \& Atance, C. M. (2019). Children's behavior and spontaneous talk in a future thinking task. Psychological research, 83(4), 761-773.

Chernyak, N., Leech, K. A., \& Rowe, M. L. (2017). Training preschoolers' prospective abilities through conversation about the extended self. Developmental Psychology, 53(4), 652.

DeLoache, J. S. (2004). Becoming symbol-minded. Trends in cognitive sciences, 8(2), 66-70.

Dueck, K., Castro, A., Atance, C., Kamawar, D., \& Milyavskaya, M. (2019) Children's saving in a token-based task and its relation to household income and parental education. Department of Psychology, University of Ottawa, Carleton University.

Fabricius, W. V. (1988). The development of forward search planning in preschoolers. Child development, 1473-1488.

Fagot, B. I., \& Gauvain, M. (1997). Mother-child problem solving: Continuity through the early childhood years. Developmental psychology, 33(3), 480.

Fuson, K. C. (1992). Relationships between counting and cardinality from age 2 to age 8 .

Gyurke, J. S., Marmor, D. S., \& Melrose, S. E. (2000). The assessment of preschool children with the Wechsler Preschool and Primary Scale of IntelligenceRevised. The psychoeducational assessment of preschool children, 3, 57-75. 
Hall, J. D., Jones, C. H., \& Claxton, A. F. (2008). Evaluation of the stop \& think social skills program with kindergarten students. Journal of Applied School Psychology, 24(2), 265-283.

Jerome \& Kamawar. (2020) Preschoolers' Saving Performance: The Role of Budgeting and Psychological Distance. Department of Psychology, Carleton University

Kamawar, D., Connolly, K., Astle-Rahim, A., Smygwaty, S., \& Vendetti, C. (2019). Preschoolers' saving behavior: The role of planning and self-control. Child development, 90(4), e407-e420.

Lee, W. S., \& Atance, C. M. (2016). The effect of psychological distance on children's reasoning about future preferences. PloS one, 11(10), e0164382.

Mazachowsky, T. R., Koktavy, C., \& Mahy, C. E. (2019). The effect of psychological distance on young children's future predictions. Infant and Child Development, 28(4), e2133.

McColgan, K. L., \& McCormack, T. (2008). Searching and planning: Young children's reasoning about past and future event sequences. Child Development, 79(5), 1477-1497.

McCormack, T., \& Atance, C. M. (2011). Planning in young children: A review and synthesis. Developmental Review, 31(1), 1-31.

Metcalf, J. L., \& Atance, C. M. (2011). Do preschoolers save to benefit their future selves?. Cognitive Development, 26(4), 371-382.

Mischel, W., Shoda, Y., \& Rodriguez, M. I. (1989). Delay of gratification in children. Science, 244(4907), 933-938. 
Moses, L. J., Carlson, S. M., Stieglitz, S., \& Claxton, L. J. (2003). Executive function, prepotency, and children's theory of mind. Unpublished manuscript.

Nyhus, E. K., \& Webley, P. (2001). The role of personality in household saving and borrowing behaviour. European journal of personality, 15(S1), S85-S103.

Owen, A. B. (1997). Scrambled net variance for integrals of smooth functions. The Annals of Statistics, 25(4), 1541-1562.

Owen, A. M. (1997). Cognitive planning in humans: neuropsychological, neuroanatomical and neuropharmacological perspectives. Progress in neurobiology, 53(4), 431-450.

Pellicano, E. (2007). Links between theory of mind and executive function in young children with autism: Clues to developmental primacy. Developmental psychology, 43(4), 974.

Prelec, D., \& Loewenstein, G. (1998). The red and the black: Mental accounting of savings and debt. Marketing science, 17(1), 4-28.

Rabinovich, A., \& Webley, P. (2007). Filling the gap between planning and doing: Psychological factors involved in the successful implementation of saving intention. Journal of Economic Psychology, 28(4), 444-461.

Raghubir, P., \& Srivastava, J. (2008). Monopoly money: The effect of payment coupling and form on spending behavior. Journal of experimental psychology: Applied, 14(3), 213.

Russell, J., Alexis, D., and Clayton, N. S. (2010). Episodic future thinking in 3-5 yearold children: the ability to thinking of what will be needed from a different point of view. Cognition 114, 56-71. doi: 10.1016/j.cognition.2009.08.013 
Sarnecka, B. W., \& Carey, S. (2008). How counting represents number: What children must learn and when they learn it. Cognition, 108(3), 662-674.

Scholnick, E. K., Friedman, S. L., \& Wallner-Allen, K. E. (1997). What do they really measure? A comparative analysis of planning tasks. The developmental psychology of planning: Why, how, and when do we plan, 127-156.

Simon, H. A. (1975). The functional equivalence of problem solving skills. Cognitive psychology, 7(2), 268-288.

Sonuga-Barke, E. J., \& Webley, P. (1993). Children's saving: A study in the development of economic behaviour. Psychology Press.

Wellman, H. M., Cross, D., \& Watson, J. (2001). Meta-analysis of theory-of-mind development: The truth about false belief. Child development, 72(3), 655-684.

Willoughby, M. T., Blair, C. B., Wirth, R. J., \& Greenberg, M. (2010). The measurement of executive function at age 3 years: psychometric properties and criterion validity of a new battery of tasks. Psychological assessment, 22(2), 306.

Zelazo, P. D., \& Carlson, S. M. (2012). Hot and cool executive function in childhood and adolescence: Development and plasticity. Child development perspectives, 6(4), 354-360.

Zelazo, P. D., Qu, L., \& Kesek, A. C. (2010). Hot executive function: Emotion and the development of cognitive control. 
Appendix A

Token-Saving Paradigm Protocol

\section{Introduction}

- I'm going to show you two games today. One game is on the green tray [point to

Materials green tray] and one game is on the blue tray [point to blue tray].

- I have some different prizes for these games.

Do you know what these are called? [Point to both types of stickers]

$\bullet$

○ *If "stickers" $\rightarrow$ That's right, these are stickers.

$\circ \quad *$ If other response $\rightarrow$ Actually, these are stickers.

- Do you know what these are? [Point to both types of toys]

○ *If "toys" $\rightarrow$ That's right, these are toys.

$\circ \quad *$ If other response $\rightarrow$ Actually, these are toys.

- So, there are two games: the stickers game and the toys game.

\section{Tokens}

- I have something else for these games. [Show child seven tokens]

- Do you know what these are called? [Point to tokens]

$\circ \quad$ *If "tokens" $\rightarrow$ That's right, these are called tokens

$\circ *$ If other response $\rightarrow$ In these games, these are called tokens.

\section{Preferences}

Ask the child which type of stickers they like more. (Circle response)

\section{Which stickers do you like more? $\quad$ Sticker option \#1 $\quad$ Stickers option \#2} [point to each] These or these?

*Put the ones they don't like as much away

- Ask the child which type of toys they like more. (Circle response)

\begin{tabular}{|lll|}
\hline $\begin{array}{l}\text { Which toys do you like more? } \\
\text { [point to each] These or these? }\end{array}$ & Toy option \# 1 & Toy option \# 2 \\
\hline
\end{tabular}

*Put the ones they don't like as much away 


\section{Explanations:}

- Now, I'm going to show you how to play the two games and then you will get your turn.

How to play the stickers game:

- This is the stickers game. It is on the green tray. [Point to green tray]

- In this game, one token gets you one prize.

- Let me show you how it works.

- If I want a sticker, I have to put one token into this green box. [Put token in green box]

- Now I can have one sticker. [take one sticker from the bowl]

- Remember, the rule is, once you put a token in the box you can't take it out because it is all used up.

- That is how you play the stickers game.

How to play the toys game:

- This is the toys game. It is on the blue tray. [Point to blue tray]

- In this game, one token gets you one prize.

- Let me show you how it works.

- If I want a toy, I have to put one token into this blue box. [Put token in blue box]

- Now I can have one toy. [Take one toy from the bowl]

- Remember, the rule is, once you put a token in the box you can't take it out because it is all used up.

Preference check

- Ask the child which prize they like more, between their preferred stickers and preferred toys. (Circle response)

Which do you like more? Stickers Toys

[point to each] These or these?

Record task order: (circle response)

- *Always present less-preferred stimulus (e.g., the one they like less) first

Record task order:

First stimulus: Stickers Toys

Second stimulus: $\quad$ Stickers Toys 
Explanations:

- Now it is almost your turn.

- First, I will put the stickers game on the table for three minutes. [point to green tray]

- After that, I will take the stickers game away and put the toys game on the table for three minutes. [point to blue tray]

Memory check (Circle responses)

Question A

Okay, so which game will I put on the table first? Correct Incorrect Don't Know No Answer

*If "stickers/green" $\rightarrow$ That's right, you will get the green tray with the stickers game.

*If "blue/toys" $\rightarrow$ No, you will get the green tray with the stickers game.

*If other response $\rightarrow$ You will get the green tray with the stickers game.

*If incorrect, repeat memory check question

Okay, so which game will I put on the table first? Correct Incorrect Don't Know No Answer

*If incorrect again, correct and continue

\section{Question B}

Okay, so which game will I put on the table after that? Correct Incorrect Don't Know No Answer

*If toys/blue $\rightarrow$ That's right, after the stickers game, you will get the blue tray with the toys game.

*If green/stickers $\rightarrow$ No, after the stickers game, you will get the blue tray with the toys game.

*If I don't know $\rightarrow$ After the stickers game, you will get the blue tray with the toys game.

*If incorrect, repeat memory check question

Okay, so which game will I put on the table after that? Correct Incorrect Don't Know No Answer

*If incorrect again, correct and continue.

\section{Question C}

Now, how do you get a sticker in this game? Correct Incorrect Don't Know No Answer

*If correct (e.g., put a token into the green box) $\rightarrow$ That's right, you put a token in the green box to get a sticker.

*If incorrect response $\rightarrow$ No, you put a token in the green box to get a sticker.

*If other response $\rightarrow$ You put a token in the green box to get a sticker.

*If incorrect, repeat memory check question

Now, how do you get a sticker in this game? Correct Incorrect Don't Know No Answer

*If incorrect again, correct and continue

\footnotetext{
${ }^{2}$ The protocol for the other option (stickers being the most preferred prize) will be the same, except that 'stickers' will be used instead of 'toys' throughout.
} 


\section{Question D}

Now, how do you get a toy in this game? $\quad$ Correct $\quad$ Incorrect $\quad$ Don't Know No Answer

*If correct (e.g., put a token into the blue box) $\rightarrow$ That's right, you put a token in the blue box to get a toy.

*If incorrect response $\rightarrow$ No, you put a token in the blue box to get a toy.

*If other response $\rightarrow$ You put a token in the blue box to get a toy.

*If incorrect, repeat memory check question

Now, how do you get a toy in this game? Correct Incorrect Don't Know No Answer

*If incorrect again, correct and continue

\section{Instructions:}

- Remember, one token gets you one prize, and once you put a token in the box you can't take it out.

- I am giving you five tokens to use: one, two, three, four, five. [Place tokens on table as you count them out loud, place them equidistant from both games, in a single line with equal spaces between them]

- These are all the tokens I have for you today, so once they are all used up you can't get any more prizes.

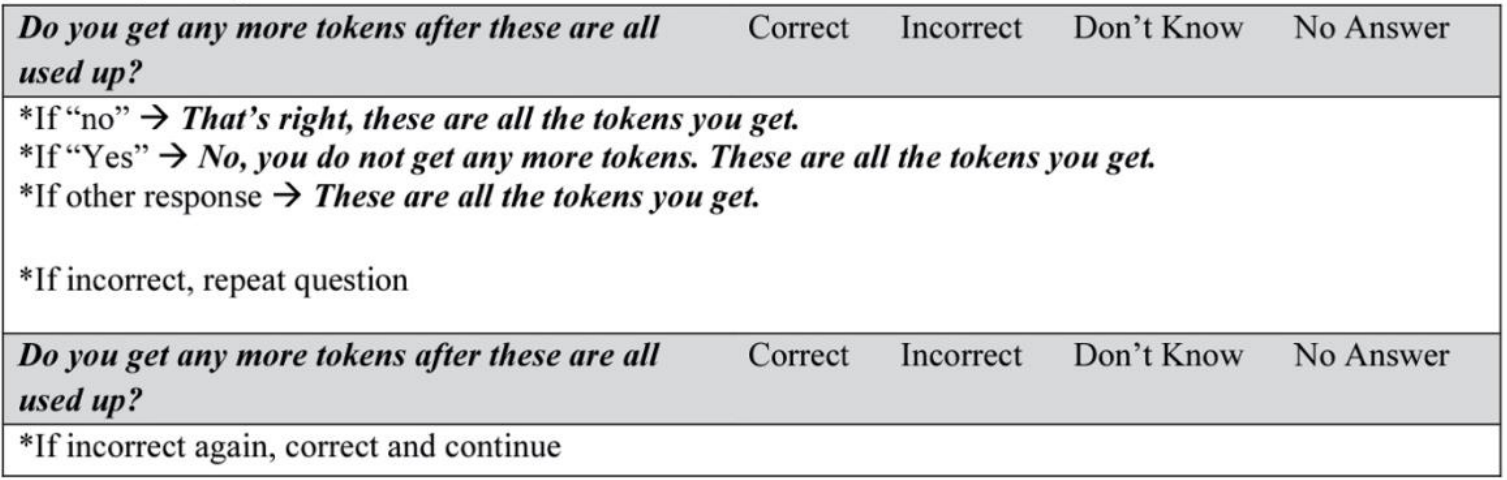




\section{Standardization Guidelines:}

If child tries to take used tokens out of the box say, “Remember, we can't use those tokens anymore"

If child attempts to interact with experimenter say, "I have to do my work over here."

\section{Start stickers game:}

- Now it is time for the stickers game.

- I am going to put the toys game away. [Put blue tray with toys out of sight and place the green tray with stickers centered on child's location; this should result in the tokens being centered in front of the tray]

- My timer is set for three minutes. That is how long you get with the stickers game.

- I am going to do some work over there.

- Let's start right now. [Turn away and pretend to work for three minutes]

Record observations using table on next page 


\begin{abstract}
Standardization Guidelines:
If child tries to take used tokens out of the box say, “Remember, we can't use those tokens anymore"

If child attempts to interact with experimenter say, "I have to do my work over here."

*Put a small flat box down in front of each tray (colour matched - one blue and one green).

*Ask the child to place the tokens they would like to use for each game in the boxes in front of each tray.
\end{abstract}

- This box is for the tokens for the stickers game [point to the box in front of the green tray]

- This box is for the tokens for the toys game [point to the box in front of the blue tray]

\title{
Memory check: (circle responses)
}

Which box is for the tokens for the stickers game? Green Blue Don't Know No Answer

*If stickers/green $\rightarrow$ That's right, that box [point] is for the stickers game.

*If toys/blue $\rightarrow$ No, that box [point] is for the stickers game.

*If I don't know $\rightarrow$ That box [point] is for the stickers game.

*If incorrect, repeat memory check question.

Okay, do you remember which box is for the stickers game? Green Blue Don't Know No Answer

*If incorrect again, correct and continue.

\begin{tabular}{l}
\hline Which box is for the tokens for the toys game? Blue Green Don't Know No Answer \\
\hline *If toys/blue $\rightarrow$ That's right, that box [point] is for the toys game. \\
*If stickers/green $\rightarrow$ No, that box [point] is for the toys game. \\
*If I don't know $\rightarrow$ That box [point] is for the toys game. \\
*If incorrect, repeat memory check question. \\
\hline Okay, do you remember which box is for the toys game? Blue Green Don't Know No Answer \\
\hline *If incorrect again, correct and continue.
\end{tabular}

- You can choose how you use your tokens. Here they are. [point to tokens, which are placed equidistant from both games, in a single line with equal spaces between them]

- Go ahead, put them in!

Number of tokens allocated to the stickers game:

Number of tokens allocated to the toys game:

- Now it is time for the stickers game.

- I am going to put the toys game away. [Put away toys game (blue tray) but leave both boxes out on the table in front of the stickers game (green tray) and follow baseline protocol.]

- My timer is set for three minutes. That is how long you get with the stickers game.

- I am going to do some work over there.

- Let's start right now. [Turn away and pretend to work for three minutes] 
Appendix B

Marble Saving Paradigm Protocol

E guides child into hallway and introduces the two rooms: You are going to get to play in two rooms. Look at this door with the red sign (E points). This picture tells us that the red room has a little marble game. Let's look inside the red room. E enters red room with child. Child directed to try the marble run with one marble. Let's try the little marble game. Put your marble here (E points to top of marble run). See how the marble goes into this bowl at the end? Once you put a marble down the hole, the marble goes into this bowl and we can't use it again. Let's go see the other room.

E guides child back out to hallway. Look at this door with the blue sign (E points). This picture means that this room has a big marble game. Let's look inside the blue room. E enters blue room with child. Child directed to try the marble run with one marble. Let's try the big marble game. Put your marble here ( $\mathrm{E}$ points to top of marble run). Remember, once the marble goes into the bowl, we can't use it again.

Ok, let's go back into the hall, I have a question for you. E guides child back into hallway, closing both testing room doors.

Preference check:

E presents child with a card that has photos of the little (left) \& big (right) marble runs. $\mathrm{E}$ points to the photo on the left "this is a picture of the little marble game." $\mathrm{E}$ points to photo on right, "this is a picture of the big marble game."

E asks: Which marble game do you like best?

(Take child to preferred room, based on preference check above, second).

If child indicates preference for complex marble run:

- Red room with little marble game is shown first.

- Photo of little run shown first (left) during marble allocation.

*Notes:

Modified for child who prefers simple marble run

Placement of photo counterbalanced

$\mathrm{E}:$ Let's see what you are going to do.

E points to the sign on the door. First you are going to stay in the red room for 3 minutes. The red room has the little marble game. After, you are going to stay in the blue room for 3 minutes $\mathrm{E}$ points to the sign on the blue door. The blue room has the big marble game.

Memory check: (a) Okay, so which room are you going to play in first? 
(b) And which marble game is in the red room?

If incorrect, repeat instructions and memory check questions

(a)

(b)

Regardless of child's response $2^{\text {nd }}$ time, E says: (Yeah...) We're going to go in the red room first. The red room has the little marble game. You only get 5 marbles today. You get to decide how many marbles you want to use in each room. Remember, once you put a marble down the hole, you can't take it out again. 
Standardization Guidelines:

If child tries to take used marbles from bottom of run say, "Remember, we can't play with those marbles anymore."

If child attempts to interact with experimenter say, "I'm doing my work right now."

\section{-Red Room-}

E guides child into red room. "Okay, we're gonna stay in the red room for 3 minutes. I'm going to do my work over here until time is up." E sets timer and places it on table, then sits at table to "work".

\begin{tabular}{|c|c|c|c|c|c|c|}
\hline Time & $\begin{array}{c}\# \\
\text { Marbles } \\
\text { used }\end{array}$ & $\begin{array}{l}\text { Plays with } \\
\text { marble on } \\
\text { floor }\end{array}$ & $\begin{array}{l}\text { Plays with } \\
\text { marble in } \\
\text { hands }\end{array}$ & $\begin{array}{l}\text { Attempts to } \\
\text { retrieve used } \\
\text { marble }\end{array}$ & $\begin{array}{c}\text { Verbalizes } \\
\text { intention to } \\
\text { save }\end{array}$ & $\begin{array}{c}\text { Other } \\
\text { Observations } \\
\text { (Verbal / } \\
\text { Behavioural) }\end{array}$ \\
\hline $\begin{array}{l}0: 00- \\
0: 29\end{array}$ & & & & & & \\
\hline $\begin{array}{l}0: 30- \\
0: 59\end{array}$ & & & & & & \\
\hline $\begin{array}{l}1: 00- \\
1: 29\end{array}$ & & & & & & \\
\hline $\begin{array}{l}1: 30- \\
1: 59\end{array}$ & & & & & & \\
\hline $\begin{array}{l}2: 00- \\
2: 29\end{array}$ & & & & & & \\
\hline $\begin{array}{l}2: 30- \\
3: 00\end{array}$ & & & & & & \\
\hline
\end{tabular}

Total \# marbles used:

Memory check: When timer goes off, E says: Okay, do you remember what we're going to do now?

If child does not spontaneously mention both the blue room and the big marble run, ask the following as necessary: So, which room are you going to play in now?

And which marble game is in the blue room?

Regardless of child's answer(s) E says: (Yeah...) We're going to go in the blue room for 3 minutes. The blue room has the big marble game. Let's bring your marbles! 
-Blue Room-

E guides child into the blue room. "Okay, we're going to stay in the blue room for 3 minutes. I'm going to do my work over here until time is up." E sets timer and places it on table, then sits at table to "work".

\begin{tabular}{|c|c|c|c|c|c|c|}
\hline Time & $\begin{array}{c}\# \\
\text { Marbles } \\
\text { used }\end{array}$ & $\begin{array}{c}\text { Plays with } \\
\text { marble on } \\
\text { floor }\end{array}$ & $\begin{array}{l}\text { Plays with } \\
\text { marble in } \\
\text { hands }\end{array}$ & $\begin{array}{l}\text { Attempts to } \\
\text { retrieve used } \\
\text { marble }\end{array}$ & $\begin{array}{c}\text { Verbalizes } \\
\text { intention to } \\
\text { save }\end{array}$ & $\begin{array}{c}\text { Other } \\
\text { Observations } \\
\text { (Verbal / } \\
\text { Behavioural) }\end{array}$ \\
\hline $\begin{array}{l}0: 00- \\
0: 29\end{array}$ & & & & & & \\
\hline $\begin{array}{l}0: 30- \\
0: 59\end{array}$ & & & & & & \\
\hline $\begin{array}{l}1: 00- \\
1: 29\end{array}$ & & & & & & \\
\hline $\begin{array}{l}1: 30- \\
1: 59\end{array}$ & & & & & & \\
\hline $\begin{array}{l}2: 00- \\
2: 29\end{array}$ & & & & & & \\
\hline $\begin{array}{l}2: 30- \\
3: 00\end{array}$ & & & & & & \\
\hline
\end{tabular}

Total \# marbles used:

\section{Test Trial 2:}

After completion of Test Trial 1, E guides child into the hallway. Guess what? I found 5 more marbles so you get to play again! The red door ( $\mathrm{E}$ points) has a picture of the little marble game on it. Do you remember what's inside the red room?

If incorrect E states, The red room has the little marble game.

The blue door (E points) has a picture of the big marble game on it. Do you remember what's inside the blue room?

If incorrect E states, The blue room has the big marble game.

E points to the sign on the red door. First you are going to stay in the red room for 3 minutes. The red room has the little marble game. After, you are going to stay in the blue room for 3 minutes. E points to the sign on the blue door. The blue room has the big marble game. 
Memory check: (a) Okay, so which room are you going to play in first?

(b) And which marble game is in the red room?

If incorrect, repeat instructions and memory check questions

(a)

Regardless of child's response $2^{\text {nd }}$ time, E says: (Yeah...) We're going to go in the red room first. The red room has the little marble game. You only get 5 marbles today. You get to decide how many marbles you want to use in each room. Remember, once you put a marble down the marble game, you can't take it out again.

\section{$\underline{\text { Test Trial } 2}$}

\section{-Red Room-}

E guides child into red room. "Okay, we're gonna stay in the red room for 3 minutes.. I'm going to do my work over here until time is up." E sets timer and places it on table, then sits at table to "work".

\begin{tabular}{|c|c|c|c|c|c|c|}
\hline Time & $\begin{array}{c}\# \\
\text { Marbles } \\
\text { used }\end{array}$ & $\begin{array}{l}\text { Plays with } \\
\text { marble on } \\
\text { floor }\end{array}$ & $\begin{array}{c}\text { Plays with } \\
\text { marble in } \\
\text { hands }\end{array}$ & $\begin{array}{l}\text { Attempts to } \\
\text { retrieve used } \\
\text { marble }\end{array}$ & $\begin{array}{c}\text { Verbalizes } \\
\text { intention to } \\
\text { save }\end{array}$ & $\begin{array}{c}\text { Other } \\
\text { Observations } \\
\text { (Verbal / } \\
\text { Behavioural) }\end{array}$ \\
\hline $\begin{array}{l}0: 29- \\
2: 30\end{array}$ & & & & & & \\
\hline $\begin{array}{l}0: 30- \\
0: 59\end{array}$ & & & & & & \\
\hline $\begin{array}{l}1: 00- \\
1: 29\end{array}$ & & & & & & \\
\hline $\begin{array}{l}1: 30- \\
1: 59\end{array}$ & & & & & & \\
\hline $\begin{array}{l}2: 00- \\
2: 29\end{array}$ & & & & & & \\
\hline $\begin{array}{l}2: 30- \\
3: 00\end{array}$ & & & & & & \\
\hline
\end{tabular}

Total \# marbles used:

Memory check: When timer goes off, E says: Okay, do you remember what we're going to do now?

If child does not spontaneously mention both the blue room and the big marble run, ask the following as necessary: So, which room are you going to play in now? 
And which marble game is in the blue room?

Regardless of child's answer(s) E says: (Yeah...) We're going to go in the blue room for 3 minutes. The blue room has the big marble game. Let's bring your marbles!

-Blue Room-

E guides child into the blue room. "Okay, we're going to stay in the blue room for 3 minutes. I'm going to do my work over here until time is up." E sets timer and places it on table, then sits at table to "work".

\begin{tabular}{|l|l|l|l|l|l|l|}
\hline Time & $\begin{array}{c}\text { Marbles } \\
\text { used }\end{array}$ & $\begin{array}{c}\text { Plays with } \\
\text { marble on } \\
\text { floor }\end{array}$ & $\begin{array}{c}\text { Plays with } \\
\text { marble in } \\
\text { hands }\end{array}$ & $\begin{array}{c}\text { Attempts to } \\
\text { retrieve used } \\
\text { marble }\end{array}$ & $\begin{array}{c}\text { Verbalizes } \\
\text { intention to } \\
\text { save }\end{array}$ & $\begin{array}{c}\text { Other } \\
\text { Observations } \\
\text { (Verbal / } \\
\text { Behavioural) }\end{array}$ \\
\hline $0: 00-$ \\
$0: 29$
\end{tabular}


Now I'm going to give you two bowls. This (E points to bowl) is for the marbles for the little marble game (E points to picture of little marble run). This (E points to bowl) is for the marbles for the big marble game ( $\mathrm{E}$ points to picture of big marble run).

Memory Check: (a) Okay, so which game is this bowl for?

(b) And which game is this bowl for?

If incorrect, repeat descriptions and memory check questions:

(a)

(b)

Regardless of child's response $2^{\text {nd }}$ time, E says: (Yeah...) This (E points to bowl) is for the marbles for the little marble game (E points to picture of little marble run). This ( $\mathrm{E}$ points) is for the marbles for big marble game ( $\mathrm{E}$ points to picture of big marble run).

E: Here you go! Put them in! (E gives child shallow box with 5 marbles inside)

Standardization Guidelines:

If child tries to take used marbles from bottom of run say, "Remember, we can't play with those marbles anymore."

If child asks to use marbles in the bowl for the blue room say, " $I$ 'm doing my work right now."

-Red Room-

E guides child into red room. "Okay, we're gonna stay in the red room for 3 minutes. Let's bring your bowls. I'm going to do my work over here until time is up." E sets timer and places it on table, then sits at table to "work".

\begin{tabular}{|c|c|c|c|c|c|c|c|}
\hline Time & $\begin{array}{c}\# \\
\text { Marbles } \\
\text { used }\end{array}$ & $\begin{array}{c}\text { Plays } \\
\text { with } \\
\text { marble } \\
\text { on } \\
\text { floor }\end{array}$ & $\begin{array}{c}\text { Plays } \\
\text { with } \\
\text { marble } \\
\text { in } \\
\text { hands }\end{array}$ & $\begin{array}{c}\text { Attempts } \\
\text { to } \\
\text { retrieve } \\
\text { used } \\
\text { marble } \\
\end{array}$ & $\begin{array}{c}\text { Verbalizes } \\
\text { intention } \\
\text { to save }\end{array}$ & $\begin{array}{c}\text { Takes } \\
\text { marble(s) } \\
\text { out of } \\
\text { 'savings' } \\
\text { bowl } \\
\end{array}$ & $\begin{array}{c}\text { Other Observations } \\
\text { (Verbal / Behavioural) }\end{array}$ \\
\hline $\begin{array}{l}0: 00- \\
0: 29\end{array}$ & & & & & & & \\
\hline $\begin{array}{l}0: 30- \\
0: 59\end{array}$ & & & & & & & \\
\hline $\begin{array}{l}1: 00- \\
1: 29\end{array}$ & & & & & & & \\
\hline $\begin{array}{l}1: 30- \\
1: 59\end{array}$ & & & & & & & \\
\hline
\end{tabular}




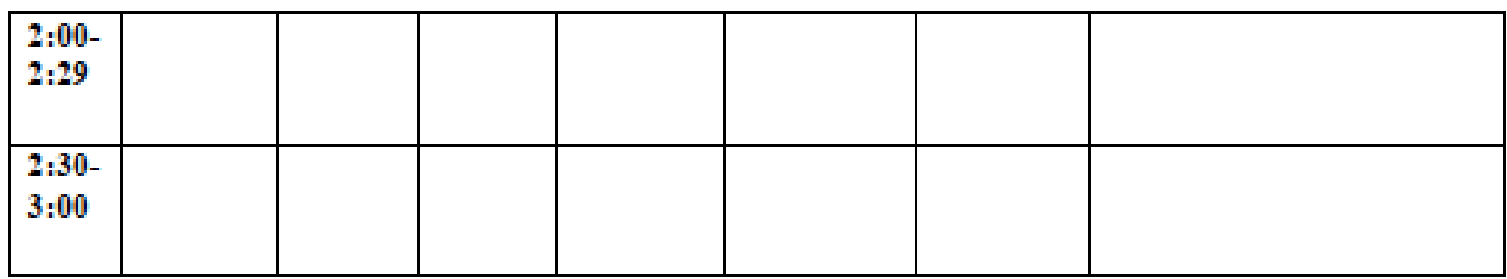

Total \# marbles used: Total used - little bowl Total used - small bowl

Memory check: When timer goes off, E says: Okay, do you remember what we're going to do now?

If child does not spontaneously mention both the blue room and the big marble run, ask the following as necessary: So, which room are you going to play in now?

\section{And which marble game is in the blue room?}

Regardless of child's answer(s) E says: (Yeah...) We're going to go in the blue room for 3 minutes. The blue room has the big marble game. Let's bring your bowls!

\section{-Blue Room-}

E guides child into the blue room. "Okay, we're going to stay in the blue room for 3 minutes. I'm going to do my work over here until time is up." E sets timer and places it on table, then sits at table to "work".

\begin{tabular}{|c|c|c|c|c|c|c|c|}
\hline Time & $\begin{array}{c}\# \\
\text { Marbles } \\
\text { used }\end{array}$ & $\begin{array}{c}\text { Plays } \\
\text { with } \\
\text { marble } \\
\text { on } \\
\text { floor }\end{array}$ & $\begin{array}{c}\text { Plays } \\
\text { with } \\
\text { marble } \\
\text { in } \\
\text { hands }\end{array}$ & $\begin{array}{c}\text { Attempts } \\
\text { to } \\
\text { retrieve } \\
\text { used } \\
\text { marble } \\
\end{array}$ & $\begin{array}{c}\text { Verbalizes } \\
\text { intention } \\
\text { to save }\end{array}$ & $\begin{array}{c}\text { Takes } \\
\text { marble(s) } \\
\text { out of } \\
\text { 'savings' } \\
\text { bowl } \\
\end{array}$ & $\begin{array}{c}\text { Other Observations } \\
\text { (Verbal / Behavioural) }\end{array}$ \\
\hline $\begin{array}{l}0: 00- \\
0: 29\end{array}$ & & & & & & & \\
\hline $\begin{array}{l}0: 30- \\
0: 59\end{array}$ & & & & & & & \\
\hline $\begin{array}{l}1: 00- \\
1: 29\end{array}$ & & & & & & & \\
\hline $\begin{array}{l}1: 30- \\
1: 59\end{array}$ & & & & & & & \\
\hline $\begin{array}{l}2: 00- \\
2: 29\end{array}$ & & & & & & & \\
\hline
\end{tabular}




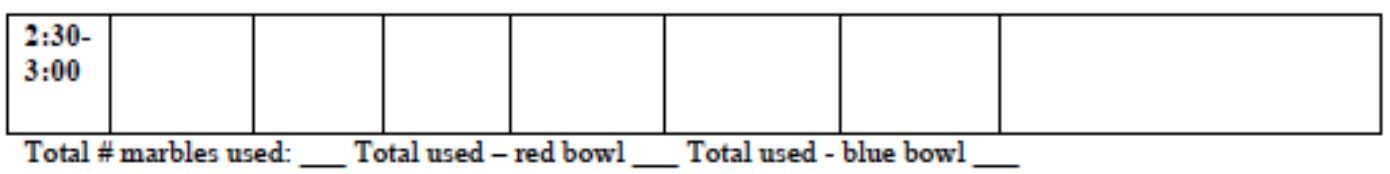

\section{Test Trial 2:}

After completion of Test Trial 1, E guides child into the hallway. Guess what? I found 5 more marbles so you get to play again! The red door (E points) has a picture of the little marble game on it. Do you remember what's inside the red room?

If incorrect E states, The red room has the little marble game.

The blue door (E points) has a picture of the big marble game on it. Do you remember what's inside the blue room?

If incorrect E states, The blue room has the big marble game.

E points to the sign on the red door. First you are going to stay in the red room for 3 minutes. The red room has the little marble game. After, you are going to stay in the blue room for 3 minutes. E points to the sign on the blue door. The blue room has the big marble game.

Memory check: (a) Okay, so which room are you going to play in first?

(b) And which marble game is in the red room?

If incorrect, repeat instructions and memory check questions

(b)

(c)

Regardless of child's response $2^{\text {nd }}$ time, E says: (Yeah...) We're going to go in the red room first. The red room has the little marble game. You only get 5 marbles today. You get to decide how many marbles you want to use in each room. Remember, once you put a marble down the marble game, you can't take it out again.

Okay, here are our bowls. (E points to bowl with picture of little marble run).

Do you remember which game this bowl is for?

If child does not mention the little marble game, E states: This (E points) is for the marbles you want to use in the red room with the little marble game (E points to picture of little marble run).

(E points to bowl with picture of big marble run). Do you remember which game this bowl is for? 
If child does not mention the big marble game, E states: This bowl (E points) is for the marbles you want to use in the blue room with the big marble game. (E points to picture of big marble game).

E: Here you go! Put them in! (E gives child shallow box with 5 marbles inside)

\section{$\underline{\text { Test Trial } 2}$}

-Red Room-

E guides child into red room. "Okay, we're gonna stay in the red room for 3 mimutes. Let's bring your bowls. I'm going to do my work over here until time is up." E sets timer and places it on table, then sits at table to "work".

\begin{tabular}{|c|c|c|c|c|c|c|c|}
\hline Time & $\begin{array}{c}\# \\
\text { Marbles } \\
\text { used }\end{array}$ & $\begin{array}{c}\text { Plays } \\
\text { with } \\
\text { marble } \\
\text { on } \\
\text { floor }\end{array}$ & $\begin{array}{c}\text { Plays } \\
\text { with } \\
\text { marble } \\
\text { in } \\
\text { hands }\end{array}$ & $\begin{array}{c}\text { Attempts } \\
\text { to } \\
\text { retrieve } \\
\text { used } \\
\text { marble }\end{array}$ & $\begin{array}{c}\text { Verbalizes } \\
\text { intention } \\
\text { to save }\end{array}$ & $\begin{array}{c}\text { Takes } \\
\text { marble(s) } \\
\text { out of } \\
\text { 'savings' } \\
\text { bowl }\end{array}$ & $\begin{array}{c}\text { Other Observations } \\
\text { (Verbal / Behavioural) }\end{array}$ \\
\hline $\begin{array}{l}0: 29- \\
2: 30\end{array}$ & & & & & & & \\
\hline $\begin{array}{l}0: 30- \\
0: 59\end{array}$ & & & & & & & \\
\hline $\begin{array}{l}1: 00- \\
1: 29\end{array}$ & & & & & & & \\
\hline $\begin{array}{l}1: 30- \\
1: 59\end{array}$ & & & & & & & \\
\hline $\begin{array}{l}2: 00- \\
2: 29\end{array}$ & & & & & & & \\
\hline $\begin{array}{l}2: 30- \\
3: 00\end{array}$ & & & & & & & \\
\hline
\end{tabular}

Memory check: When timer goes off, E says: Okay, do you remember what we're going to do now?

If child does not spontaneously mention both the blue room and the big marble run, ask the following as necessary: So, which room are you going to play in now?

And which marble game is in the blue room?

Regardless of child's answer(s) E says: (Yeah...) We're going to go in the blue room for 3 minutes. The blue room has the big marble game. Let's bring your bowls! 
-Blue Room-

E guides child into the blue room. "Okay, we're going to stay in the blue room for 3 minutes. I'm going to do my work over here until time is up." E sets timer and places it on table, then sits at table to "work".

\begin{tabular}{|c|c|c|c|c|c|c|c|}
\hline Time & $\begin{array}{c}\# \\
\text { Marbles } \\
\text { used }\end{array}$ & $\begin{array}{c}\text { Plays } \\
\text { with } \\
\text { marble } \\
\text { on floor }\end{array}$ & $\begin{array}{c}\text { Plays } \\
\text { with } \\
\text { marble } \\
\text { in hands }\end{array}$ & $\begin{array}{c}\text { Attempts } \\
\text { to retrieve } \\
\text { used } \\
\text { marble }\end{array}$ & $\begin{array}{c}\text { Verbalizes } \\
\text { intention to } \\
\text { save }\end{array}$ & $\begin{array}{c}\text { Takes } \\
\text { marble(s) } \\
\text { out of } \\
\text { 'savings' } \\
\text { bowl } \\
\end{array}$ & $\begin{array}{c}\text { Other } \\
\text { Observations } \\
\text { (Verbal/ } \\
\text { Behavioural) }\end{array}$ \\
\hline $\begin{array}{l}0: 00- \\
0: 29\end{array}$ & & & & & & & \\
\hline $\begin{array}{l}0: 30- \\
0: 59\end{array}$ & & & & & & & \\
\hline $\begin{array}{l}1: 00- \\
1: 29\end{array}$ & & & & & & & \\
\hline $\begin{array}{l}1: 30- \\
1: 59\end{array}$ & & & & & & & \\
\hline $\begin{array}{l}2: 00- \\
2: 29\end{array}$ & & & & & & & \\
\hline $\begin{array}{l}2: 30- \\
3: 00\end{array}$ & & & & & & & \\
\hline
\end{tabular}

Total \# marbles used: ___ Total used - red bowl __ Total used - blue bowl 
Appendix C

Truck Loading Protocol

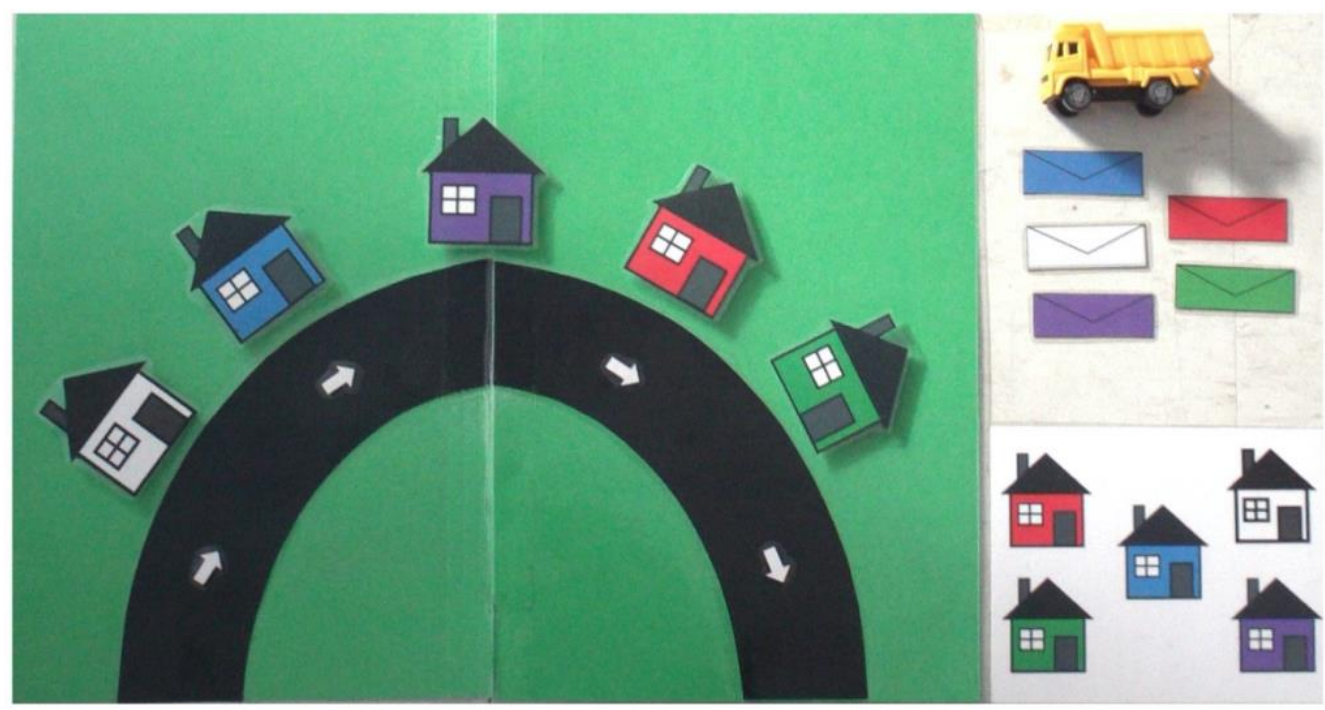

Truck Loading Task protocol:

Colour check: (place sheet with colours on table)

Can you show me Purple? Yellow? Green? Blue? Red? (randomize)

Record accuracy:

Purple Yellow Green Blue Red

(start with yellow house and envelope)

O.K. Now we're going to play a new game. Let's pretend that you're a mail carrier. We're going to have a party and I need you to deliver this party invitation to this house (point)

See, the yellow invitation goes to the yellow house. First, we need to load the truck (let child place yellow invitation in back of truck)

Direction Rule

Now this is a one-way street which means that you can only drive this way with the truck (point with finger). You have to follow the arrows. Why don't you deliver the yellow 
invitation to the yellow house? (place truck at start, and have child drive the truck all the way around the road, back to the start).

If incorrect: O.K. remember this is a one-way street, so you need to drive around like this $($ demo $)$. Why don't you try again?

Total \# of tries until correct ( $\max 3$, then continue):

O.K.! (take back yellow invitation)

Order Rule

(add purple house) Now there are two houses that we want to invite to the party. The yellow invitation goes to the yellow house and the purple invitation goes to the purple house (point)

Now, we need to deliver these party invitations fast so that everyone will be able to come to the party. The fastest way is to drive around the block only one time.

We need to put the invitations in the back of the truck so that the top invitation goes to the house that you are driving by. You always have to take the invitation off the top of the truck so that the top invitation goes to the first house and the next invitation goes to the next house.

So now we need to load the truck. Let's see here, it looks like the first house you will drive by is the yellow house, so the yellow invitation has to go on the very top.

And the second house you will drive by is the purple house, so the purple invitation needs to go on the bottom.

So first let's put in the purple invitation and then put in the yellow invitation.

(Pile the 2 invitations in truck, one at a time.)

Now, remember, we can only take an invitation from the top of the truck. We can never take an invitation from the bottom of the truck. So, can I take one from the bottom like this? (demo)

No way!

If yes, repeat until says no ( $\max 3$ times, then continue)

Total \# of tries until correct:

Now let's deliver the invitations. Why don't you drive? (try and have $C$ deliver the invitations, but help if needed) See, now as I drive by, I can first deliver the yellow invitation to the yellow house and then next I can deliver the purple invitation to the purple house. Yeah, now everyone can come to the party!

LEVEL 1: 2 houses 
(Place red then green). Here's a red invitation for the red house and a green invitation for the green house (point).

Now it's your turn to deliver the party invitations to all of the houses on the block so that everyone can come to the party. O.K., remember the rules, each colour invitation goes to the same colour house, and you need to follow the arrows around the block because this is a one-way street. And when delivering the invitations, you can only take the top invitation; you can never take one from the bottom.

Here are the invitations. (Place down, red slightly to C's left and green slightly to right)

O.K., now it's your turn to load the truck.

CORRECT

Good job! Let's add another house.

INCORRECT (remind of rule broken and circle)

[colour rule] Whoops! Remember each colour invitation goes to each colour house

[direction rule] Whoops! Remember this is a one-street, so you have to follow the arrows. You can only drive in one direction, no backing up. [order rule] Whoops! Remember you can only take an invitation from the top of the truck. You can never take an invitation from the bottom of the truck. [tries to drive around block another time] Whoops! We ran out of time. It's time for the party to start. Remember you can only drive around the block once.

TRIAL 1: PASS (go to next level) FAIL (repeat; This one is a hard one. Let's try again).

TRIAL 2: PASS (go to next level) FAIL (stop)

\section{LEVEL 2: 3 houses}

Now let's pretend that there are 3 houses on the block and you want to invite all 3 houses to the party (place blue, yellow, green). Here's a blue invitation for the blue house. Here's a yellow invitation for the yellow house. And here's a green invitation for the green house (point).

Here are the invitations (place down, green slightly to C's left, blue in front, and yellow slightly to right)

Go ahead and load up the truck.

CORRECT

Good job! Let's add another house.

INCORRECT (remind of rule broken and circle) 
CORRECT

Good job!

INCORRECT (remind of rule broken and circle)

[colour rule] Whoops! Remember each colour invitation goes to each colour house

[direction rule] Whoops! Remember this is a one-street, so you have to follow the arrows. You can only drive in one direction, no backing up.

[order rule] Whoops! Remember you can only take an invitation from the top of the truck. You can never take an invitation from the bottom of the truck. [tries to drive around block another time] Whoops! We ran out of time. It's time for the party to start. Remember you can only drive around the block once.

TRIAL 1: PASS (stop)

FAIL (repeat; This one is a hard one. Let's try again).

TRIAL 2: PASS (stop)

FAIL (stop)

Great job!

TOTAL NUMBER OF TRIALS:

HIGHEST LEVEL ACHIEVED: 


\section{Appendix D}

Normal Q-Q Plot of Age of Child

Figure 1.

Normal Q-Q plot of age of child (in months)

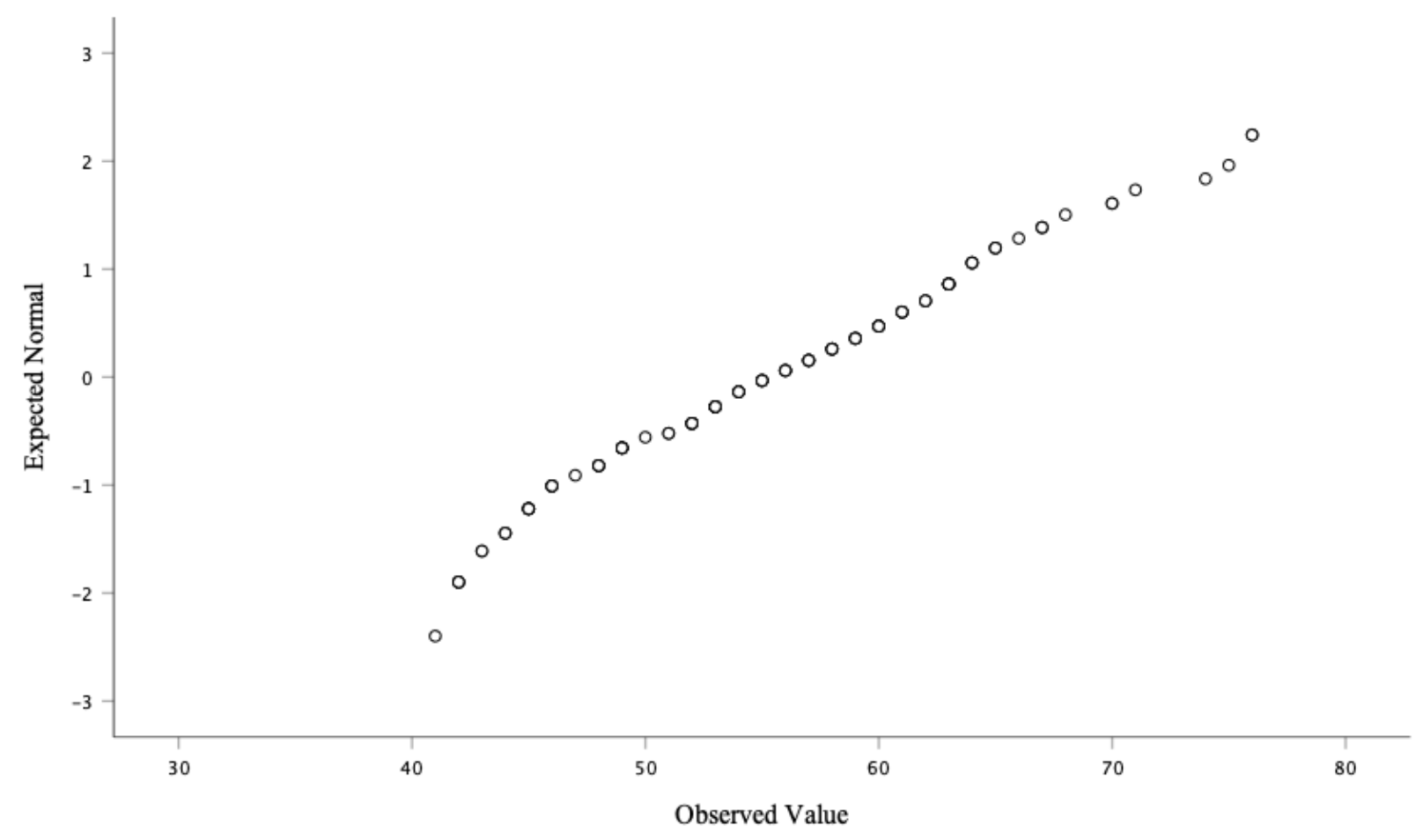




\section{Appendix E}

Detrended Normal Q-Q Plot of Age of child

Figure 2.

Detrended Normal Q-Q Plot of Age of Child (in months)

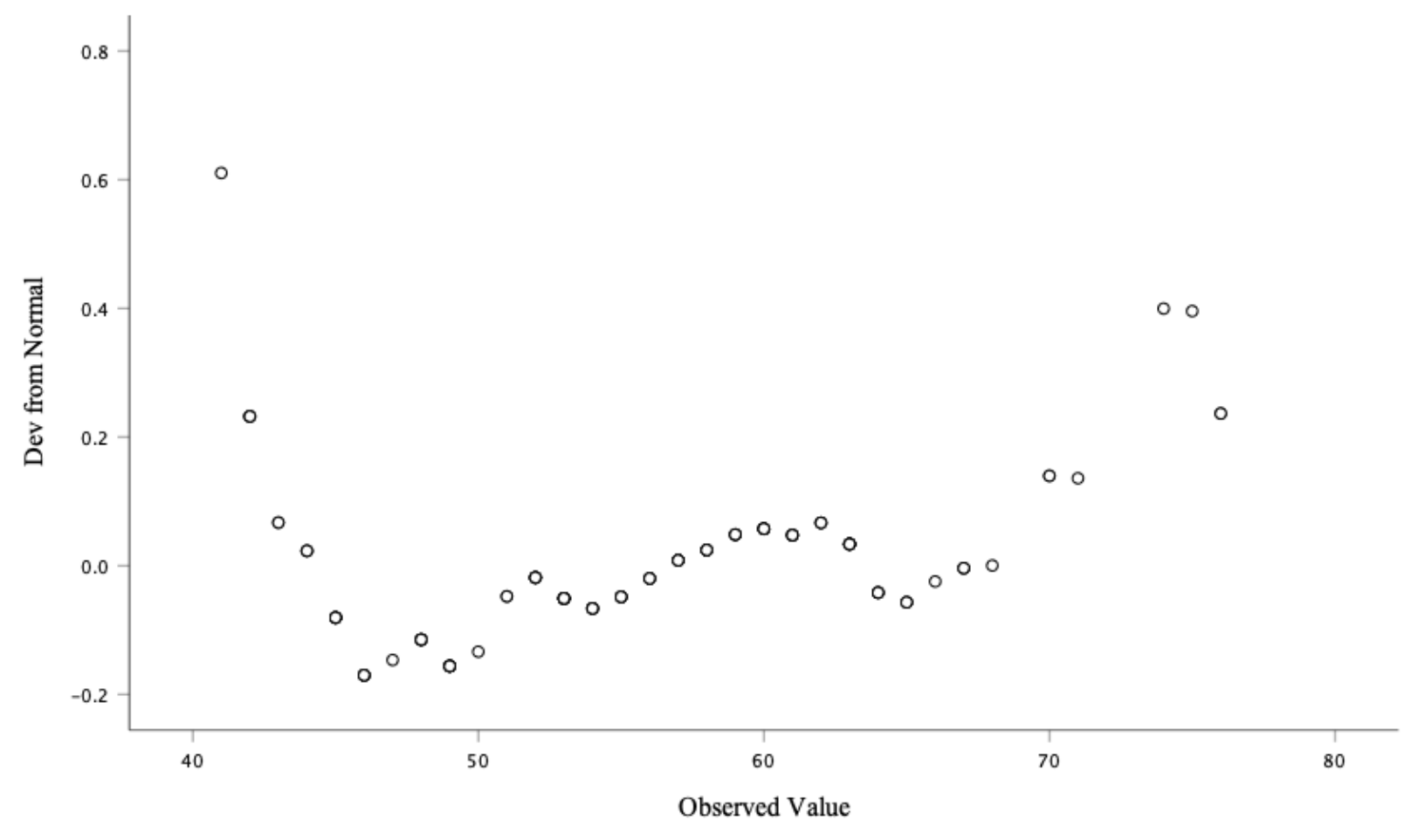

